Florida International University FIU Digital Commons

6-11-1997

\title{
Contingent-relations description facilitates rule- following in a subsequent generalization task
}

Noel Alexander Crooks

Florida International University

DOI: $10.25148 /$ etd.FI14061545

Follow this and additional works at: https://digitalcommons.fiu.edu/etd

Part of the Psychology Commons

\section{Recommended Citation}

Crooks, Noel Alexander, "Contingent-relations description facilitates rule-following in a subsequent generalization task" (1997). FIU Electronic Theses and Dissertations. 2670.

https://digitalcommons.fiu.edu/etd/2670 
FLORIDA INTERNATIONAL UNIVERSITY

Miami, Florida

CONTINGENT-RELATIONS DESCRIPTION FACILITATES RULEFOLLOWING IN A SUBSEQUENT GENERALIZATION TASK

A thesis submitted in partial satisfaction of the requirements for the degree of

MASTERS OF SCIENCE

IN

PSYCHOLOGY

by

Noel Alexander Crooks

1998 
To: Dean Arthur W. Herriott

College of Arts and Sciences

This thesis, written by Noel A. Crooks, and entitled Contingent-Relations Description Facilitates Rule-following in a Subsequent Generalization Task, having been approved in respect to style and intellectual content, is referred to you for judgement.

We have read this thesis and recommend that it be approved.

Michael R. Markham

Martha Pelaez-Nogueras

Co-Chair

Jacob L. Gewirtz, Major Professoı

Co-Chair

Date of Defense: Friday, June 11, 1997

The thesis of Noel Alexander Crooks is approved.

Dean Arthur W. Herriott

Collegę of Arts and Sciences

Dr. Richard L. Campbell

Dean of Graduate Studies

Florida International University, 1998 


\section{ACKNOWLEDGMENTS}

I would like to thank the members of my committee, Dr. Jacob Gewirtz, Dr. Martha Palaez-Norgueras and Dr. Michael Markham for their contributions and greatly appreciated comments. Special thanks to my thesis co-chairs, Dr. Martha PalaezNorgueras and Dr. Jacob Gewirtz for their patience, support and guidance. Thanks also to Dr. Michael Markham and Jerry Galindo for their ingenious computer programming. This project could not have been completed without their contributions.

This thesis is dedicated to my family whose support is immeasurable. Special thanks to Dr. Mary Levitt, Dr. Marsha Silver, Kerrie Lum Lock and Aida Sanchez for their emotional support throughout this project. I love you all. 


\section{ABSTRACT OF THE THESIS \\ CONTINGENT-RELATIONS DESCRIPTION FACILITATES RULE- FOLLOWING IN A SUBSEQUENT GENERALIZATION TASK}

by

Noel Alexander Crooks

Florida International University, 1998

Miami, Florida

Professor Jacob L. Gewirtz, Major Professor

Professor Martha Pelaez-Nogueras, Co-Chair

The present study examined if the opportunity to describe contingent relations after a matching-to-sample conditional-discrimination training procedure differentially affected participants' performances on a generalization task; and if verbal feedback differentially affected the number of trials-to-criterion during training. Eighty college students were randomly assigned to one of four groups ( $\mathrm{N}=20$ /group). Group 1 received verbal feedback congruent with computer generated contingencies. Group 2 received verbal feedback incongruent with these contingencies. Group 3 received no verbal feedback but was asked to write a description of their correct responses before the generalization test. Group 4 received neither verbal feedback nor the opportunity to write any descriptions. A difference was found between Groups 3 and 4 in the mean number of correct responses in the generalization test. Results suggest that describing experienced contingent relations facilitates the application of rule-following behaviors on subsequent generalization tasks. 
CHAPTER

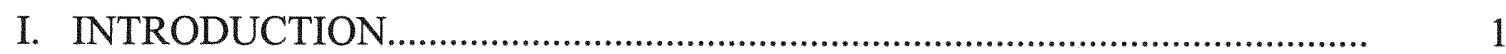

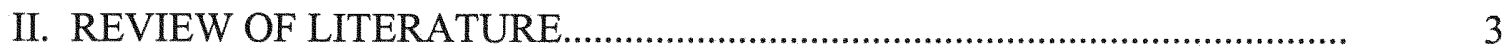

Rule-Governed Behavior...................................................................................

Role of Verbal Behavior...................................................................................

Instructions and Sensitivity to Schedules............................................................... 6

Instructions and Errorless Performance................................................................

Stimulus Equivalence and Rule-Governed Behavior............................................ 9

Rule-Governed vs. Rule-Following Behavior...................................................... 11

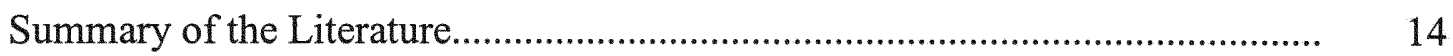

III. METHODOLOGY .................................................................................... 17

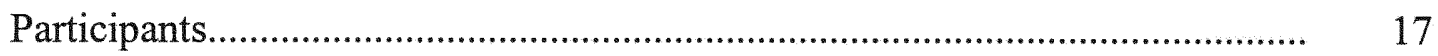

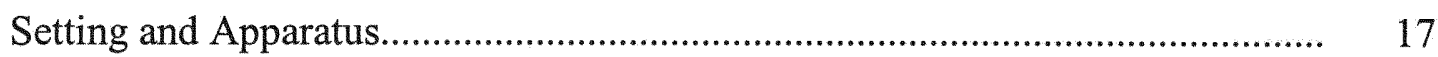

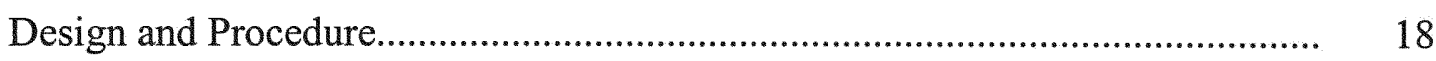

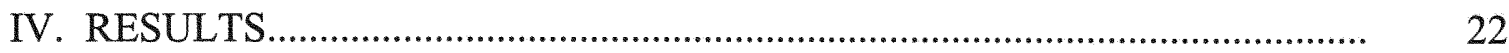

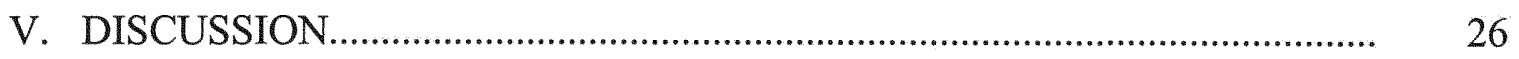

LIST OF REFERENCES.......................................................................... 30

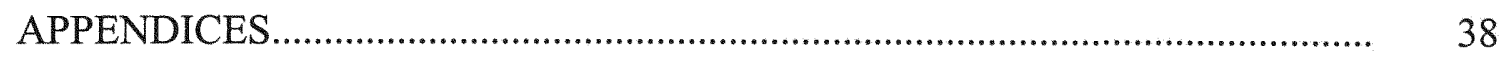




\section{Chapter 1}

\section{Introduction}

Reliable differences in the rates of responding between human and nonhuman subjects have been observed (Leander, Lippman, \& Meyer, 1968; Weiner, 1964; Weiner, 1969). These differences are usually in the form of degree of sensitivity to schedules of reinforcement. Such differences in responding have often been attributed to the mediating effects of verbal behavior in the older human subjects (e.g., Bentall, Lowe, \& Beasty, 1985; Harzem, Lowe \& Bagshaw, 1978). As a result, researchers have studied the effects of verbal behavior (often using instructions and feedback) on nonverbal as well as verbal responding (e.g., Catania, Matthews, \& Shimoff, 1982; Hayes \& Hayes, 1992), which has facilitated the analysis of rule-governed and rule-following behavior in humans.

To date, many studies have systematically examined the extent to which verbal behavior affect participants' performances when other competing contingencies are in place (e.g., Bentall, Lowe \& Beasty, 1985; Buskist \& Miller, 1986; Catania, Matthews \& Shimoff, 1982; Hayes, Brownstein, Zettle, Rosenfarb \& Korn, 1986; Hayes, Brownstein, Haas \& Greenway, 1986; Lowe, Beasty \& Bentall, 1983; Pouthas, Droit, Jacquet \& Weardon, 1990; Shimoff, Matthews \& Catania, 1986). Others have looked at the role of verbal behavior in facilitating correct responses in matching-to-sample conditionaldiscrimination tasks (e.g., Ribes-Inesta \& Martinez-Sanchez, 1990; Trigo, MartinezSanchez \& Moreno, 1995). However, the extent to which the subjects' opportunity to 
describe of contingent relations facilitates subsequent rule-following in generalization/transfer tasks requires further investigation.

The present study had two aims. The first aim was to expand the work of Trigo et al. (1995) by investigating if participants, who were given the opportunity to describe the contingent relations before a generalization test condition, produce a higher number of correct responses in this test phase than participants who were not given the opportunity to describe these contingent relations. The second aim was to investigate the extent to which direct contingencies accompanied by congruent (or incongruent) verbal feedback affect the participant's trials-to-criterion performance in a conditional-discrimination training procedure.

The assumptions underlying these theses were, first, that the opportunity to describe the contingent relations experienced during training may contribute to the participants' success in following a rule in a subsequent generalization task; and second, that the participants who had received repeated, congruent verbal feedback from an experimenter during training would achieve criterion during conditional-discrimination training in fewer trials than participants who received repeated incongruent verbal feedback during training. 
Chapter 2

Literature Review

\section{Rule-Governed Behavior versus Direct Contingency Control}

Hayes, Zettle and Rosenfarb (1989) argued that rule-governed behavior is behavior which comes in contact with two sets of contingencies. According to those authors:

"All rule-governed behavior makes contact with two types of contingencies: (1) the natural contingencies and those established by the rule and past history with rules" (p. 204).

Further distinctions between rule-following and contingency-shaped behavior have been summarized by Pelaez-Nogueras and Gewirtz (1995). The authors explain the notion that direct contingency-shaped behavior is shaped by its direct consequences and, as a result, comes under the control of nonverbal discriminative stimuli. In contrast, rulegoverned behavior involves discriminative responding shaped by the reinforcement of rule following. Rule-governed behavior can be altered by modifying either (or both) its antecedents and consequences. In contrast, contingency-shaped behavior is modified primary by its consequences. It was also argued that verbal skills are a necessary prerequisite for "true" rule-governed behavior. This is usually demonstrated by indexing the individual's compliance with instructions and requests.

Thus verbal stimuli in the form of rules indicate, specify or imply what to do, when to do it, and what will happen if one does, or does not, comply. As such, a rule 
usually implies regularity and consistency over time (Hayes \& Hayes, 1989). Skinner, (1966) conceptualized rules as "contingency-specifying stimuli". When provided, a rule is often predicted to exert stimulus control over behavior. However, the sometimes implicit nature of a rule (e.g., when it contains mands such as "Go" or "Come") adds a new dimension to traditional behavioral concepts of reinforcement, discrimination and stimulus generalization (Dinsmoor, 1995a, 1995b). In addition, contingency-specifying stimuli derived from problem solving may not have the same effects as the contingencies they specify. While direct contingencies shape behavior and alter its probability of occurrence, the probability of an occurrence based on a rule is undetermined (Skinner, 1984). As such, a rule can be described as a function-altering stimulus which may (or may not) affect the probability of a response at another time in the presence of a different stimulus (Schlinger \& Blakely, 1987; Vaughan, 1989). One may then conclude that rulefollowing and direct contingency-shaped behavior may involve related but distinct psychological processes.

The traditional approach to the study of rule-governed behavior often involves the counterpoint of "instructional control versus direct control by contingencies" (Catania, Matthews \& Shimoff, 1982; Shimoff, Matthews, \& Catania, 1986). For example, Catania, et al. (1982) investigated instructed versus shaped verbal behavior in undergraduates using button-press responses. Their results indicated that verbal responses shaped by direct-contingencies controlled nonverbal responding of the participants. However, when verbal responses were shaped by instructions, their control 
of nonverbal responding was inconsistent: they sometimes controlled, sometimes were controlled by, and at other times were independent of, the nonverbal behavior.

In an attempt to delineate the overlap between rule-following and direct contingency-shaped behaviors, Hayes, Brownstein, Haas and Greenway (1986) investigated the functional independence between the two concepts. However, they were unable to distinguish rule-following from direct contingency-shaped behaviors. This implied distinction between rule-governance and direct contingency-controlled behaviors in the past had fueled the development of methodological designs that ignored the possible interactions between these two distinct types of responding (Buskist \& Johnston, 1988; Galizio, 1987). While some would argue that human performance schedules result mainly from rule-control, others consider human-performance schedules to be the result of the interaction between rule-control and direct- contingency shaping, with the resulting behaviors now more appropriately characterized as "contingency-sustained rule-governed" behaviors (Buskist \& Miller, 1986).

The Role of Verbal Behavior

One area of controversy in the rule-governance literature involves the role of verbal behavior in the acquisition of a rule. Though many would agree that most verbal behavior is instrumental operant behavior, the cognitive implications of rules and their assumed mentalistic mediational effects have created formidable obstacles for the behavior analyst (Skinner, 1957). Some have argued that, to understand the role of verbal behavior, one would need to address the issue of how verbal behavior can influence the 
learning of other verbal and nonverbal behaviors. For example, Bentall, Lowe and Beasty (1985) investigated the role of verbal behavior in human learning, in four groups of children. The first three groups each contained three children ranging in age, respectively, between 7.5 and 9 years, 5 and 6.5 years, and 2.5 and 4 years. The fourth group consisted of four preverbal infants between six months and 1.5 years of age. Results indicated that only the behavior patterns of the preverbal infants resembled those of nonhumans. The authors attributed the differences observed in performance rates between their four groups to verbal-behavior skills that can alter operant performance. In a similar way, Pouthas, Droit, Jacquet and Weardon (1990) looked at the developmental changes in relations between verbal and nonverbal behavior in eighteen 4.5-year-old, twenty 7-year-old and twenty 11 -year-old children. The participants from all three developmental levels were exposed to an experimental session in which a consequence resulted from button-press duration. Each trial was followed also by a brief verbal probe about the contingency requirement. The 11-year-old children produced rulegoverned behavior under verbal control similar to adults. However, the button-press behavior of the 4.5-year-old children seemed to be controlled directly by reinforcement contingencies. This was true even for some of the 7-year old participants of the study who had exhibited an extensive verbal repertoire. Pouthas et al. (1990) interpreted the developmental differences in relations between verbal and nonverbal behavior as evidence of a "developmental shift" away from contingency-shaped behavior, which was the primary feature associated with the button-press response of the younger subjects ( 4.5 
and 7 years old) toward rule-governed behavior, which was the primary characteristic of the button-press response of the 11-year-old children and adults.

\section{Instructions and Sensitivity to Schedules}

Others have examined the effects of verbal behavior on the sensitivity to changing performance schedules. For example, Hayes, Brownstein, Zettle, Rosenfarb and Korn (1986) examined rule-governed behavior and sensitivity to changing consequences of button-press responding. Two experiments were conducted. In the first, four betweensubjects conditions were compared. They involved: minimal instructions, instructions to press rapidly, instructions to press slowly, and instructions indicating that sometimes rapid responding would work best and that, at other times, a slow rate would work best. The second experiment was designed to assess the relative contributions of each of the four conditions in the first experiment by presenting and then withdrawing two lights that had been paired with two specific instructions: "Go Fast" or "Go Slow". In one condition only the Go Fast light was on, in a second condition only the Go Slow light was on, and in a third the lights alternated after each minute.

The results were twofold: First, they demonstrated how instructions affect the range of behavior available in making contact with stipulated contingencies. Second, they illustrated how instructional prompts can override or modify control by the stipulated contingencies. Thus, button pressing became the definitive behavior in the three sets of relations, the pressing for points and the two types of rule following. Hayes et al. (1986) concluded that the actual rate and pattern of button pressing was the result of 
an interaction between the three sets of relations established in their second experiment. The instructions that competed with the direct contingencies in the present study were written and given at the beginning of the experiment. To date, few studies have examined the effects of such instructions (or guidance) in the form of "vocal" verbal feedback given at the end of a completed task. However, attempts have been made to investigate the relationship between self-reports and earlier performances.

For example, Critchfield and Perone (1990) used verbal self-reports of undergraduates in a delayed matching-to-sample task to examine the inconsistencies observed between participant self-reports and their actual performances. Those authors concluded that the diverse and undisclosed history of human discriminative control of target responses over self-reports is usually acquired preexperimentally and that such a history contributes to the difficulty of assessing and evaluating self-reports outside the laboratory. However, they indicated that, with the correct methodological application, the self-reports of human subjects could be sensitive to laboratory manipulation. Even so, behavioral approaches to the study of self-reports are relatively recent in experimental psychology (Critchfield \& Perone, 1993; Perone, 1988; Pilgrim \& Johnston, 1988).

\section{Instructions and Errorless Performance}

Participants can attain errorless performances once they are able to describe the specific contingency patterns operating. For example, Vaughan (1985) examined the effects of repeated acquisitions in the analysis of rule-governed behavior. Five participants, ranging in age from 3.5 to 5.5 years, were each taught a different four- 
response chain leading to conditioned reinforcement. Two experiments were carried out. The first investigated the effects of presenting "instruction" stimuli, which involved a sequence of lights over the correct response buttons, to assess their role in facilitating the acquisition of a chain of responses. It was found that, without the "instruction" stimuli, children made numerous errors before their responses were brought under the control of the programmed contingencies. Children made fewer errors with the same contingencies later in the day; but when the "instruction" stimuli were discontinued in a later session, all five participants made errors. In Vaughan's second experiment, participants were taught to verbalize the contingencies without the "instruction" stimuli. Although this resulted in errorless performance during subsequent exposures to the same procedure, errors did occur during reexposure to the procedure with the "instruction" stimuli discontinued. Vaughan (1985) concluded that, although it appeared that the children in her study could be trained to formulate instructions, these self-generated instructions occurred only when the stimulus conditions in the pre- and post-test were identical. The participants did not seem to gain from rules when the stimulus conditions involved were slightly altered. In this frame, Vaughan argued for the usefulness of collecting data from participants spanning more variegated developmental segments.

In contrast to the Pouthas et al. (1990) conclusions, Vaughan's results could be used to argue that the participants' verbalizing the contingencies had a facilitative role. That is, their verbal behavior provided the means by which a set of formal rules can be discriminated by the individual and the verbal community, regardless of whether the 
contingencies were explicit or implicit. However, the literature suggests that verbal behavior may have a more complicated function because verbal processes may interact with other behavioral processes to alter their function and their efficacy (Hayes \& Hayes, 1992; Michael, 1984; Schlinger, 1993; Schlinger \& Blakely, 1987).

\section{Stimulus Equivalence and Rule-Governed Behavior}

In rule-governance, earlier-established associations based on discriminative training may be combined in new ways (Cerutti, 1989). Cerutti argued that these associations produce more complex behaviors with characteristics that may be different from their original components. A history of these earlier behavioral components may provide a "generative springboard" that, like stimulus equivalence, may provide a possible mechanism for the emergence of novel behaviors controlled by a set of formal (verbal) rules.

For example, Hayes, Thompson and Hayes (1989) examined the relationship between stimulus equivalence and rule-following by investigating the occurrence of novel behavior patterns with respect to novel configurations of stimuli in equivalence classes. In the first experiment, functional substitutabilities were established between two independent sets of musical stimuli using equivalence procedures. Elements from the two stimulus sets were combined to produce novel stimulus configurations. Participants were able to combine components from each set to produce novel musical performances and accurate descriptions of these performances. In the second experiment, the impact of experimenter-provided names for musical-performance equivalence classes was 
investigated by creating similar classes without experimenter-provided names. The results indicated that the playing performances under these conditions were minimally affected by experimenter-provided names. This result contradicts some of the findings of Horne and Lowe (1993), who argued that naming was the basic process responsible for the formation of equivalence classes.

Thus, the results from the Hayes et al. (1989) study suggest that rules can emerge as a direct consequence of a set of behaviors, for example, playing the piano or obtaining the correct answer after adding cumulatively the values of successive numbers. The reinforcing consequence resulting from solving the problem may then lead to a corresponding strengthening of the initial set of "rules" used in the original problem-solving process. In future, a similar problem might serve as a discriminative stimulus for the generalization or selective application of this rule (i.e., rule-following) as well as for the "emergence" of some "novel" variation of the original rule set now under rule-governance.

\section{Rule-Governed versus Rule-Following Behavior}

At its most simple, rule-following means "doing what a rule tells us to do" (Hayes \& Hayes, 1989). However, some would argue that understanding a rule is not the same as following it (Parrott, 1987). Rule-following and rule-governed behaviors have distinct features which need to be addressed by the use of appropriate methodological designs. In an attempt to distinguish between rule-following and rule-governed behaviors, recent studies have focused on the conditions under which rule-governed behaviors "emerge." 
For example, Ribes-Inesta and Martinez-Sanchez (1990) studied the interaction of consequences and rule instruction in a conditional-discrimination task using a matching-to-sample procedure. They studied first, the effects of different types of instructions upon performance under delayed consequences; second, the effects of alternating different contingencies without varying instructions on performance under delayed consequences; and, third, the effects of the different schedules of consequences on the performance under nonspecific instructions.

The participants were 27 undergraduate students randomly assigned to three groups of nine. During the baseline condition, a special set of stimuli (also used for the transfer session) was presented. The participants were then asked to write on a sheet of paper, the rule they believed they had used to respond during that earlier baseline session. No feedback was provided about their written report or on their performance. Later, in a matching-to-sample task, participants were required to choose a comparison stimulus that was different from or similar to the sample stimulus. Comparison stimuli were identical to (same shape and color), similar to (same shape or color), or completely unlike (different shape and color) the sample stimulus. Feedback was given and a final report on the screen gave each participant feedback about the number of correct and incorrect responses.

Ribes-Inesta's and Martinez-Sanchez's results suggest that the instructions given in this study did not operate as rules. When participants were confronted with false or self-formulated information after responding to the true-rule instruction, they did not 
change to previously successful behavior, as would be expected with rule-governed behavior. Those authors argued for a distinction between the reporting of self-rules and the self-description of a performance during or after the completion of a task. They reasoned that this description may be based solely on the easiest perceptual arrangement during the experiment. The authors concluded that the formal presentation of instructions thought to be rules, and the occurrence of behavior controlled by these instructional contingencies, were not sufficient to indicate that rule-governed behavior occurred.

Although insufficient to test the presence or absence of rule-governed behavior, these types of tests may be sufficient to indicate the presence or absence of a specific set of rule-following behaviors controlled by experimental contingencies. A test for rulefollowing requires a less stringent procedure, for example one illustrating instructionalcontextual generalization. Appropriate tests for rule governance (or rule construction) are more difficult to construct for the behavior analyst, due in part to a greater emphasis on implied or "self-generated" behaviors associated with rule governance. Thus tests for rule governance often require new contexts or stimuli, new sets of behaviors, or new responses in order to test the "emergence" of a novel behavior controlled by a set of "rule stimuli" (Pelaez-Nogueras \& Gewirtz, 1995; Ribes-Inesta \& Martinez-Sanchez, 1990). These conceptualizations of rules are often related to the individual's problem-solving strategies (Skinner, 1966). Possible instances of the creation and acquisition of such "self-generated rules" often involve processes such as induction or deduction.

Trigo, Martinez-Sanchez and Moreno (1995) examined the relationship between 
participants' self-generated rules and their performances in a matching-to-sample task.

Twenty undergraduate participants were randomly assigned to two training groups.

Participants were asked to attend to different sets of stimuli. At the end of each session, they were to describe the correct performances and to try to generate a more-general rule. Once a performance criterion was achieved, all participants went on to a generalizationtest session. Only participants who had made up a general rule were able to perform the task correctly. The number of correct responses in the post-test did not reveal any significant differences between the type of training received. There was also no clear difference between the number of participants who formed rules in each group. The authors concluded that the results indicated a relationship between self-rules and performance but were unable to determine the directionality of these effects. The Trigo et al. (1995) study had three limitations. First, the study included a generalization test that was identical to the pretest, thus precluding the authors' ability to investigate processes beyond simple generalization (e.g., incidents of response transfer or rule-governance). Second, they did not include a control group receiving no instructions to identify a rule. As a result, the authors were unable to compare the subsequent performances of those participants who were given instructions to identify a rule with those who did not receive instructions to identify a rule.

Third, in the Trigo et al. (1995) study, a distinction between generalization and transfer was not made. Catania (1992) argues that transfer involves, Substituting one set of discriminative stimuli for another. Transfer may be based 
on common properties of two sets of stimuli or on similar correlations of the two sets of stimuli with differential contingencies. In verbal learning, transfer from one task to another is usually assessed with reference to a control group that did not learn the fist task; it is positive if the first task enhances performances on the second or negative if it does the opposite (p. 400).

In contrast, Catania (1992) argues that generalization denotes, "The spread of the effect of reinforcement in the presence of one stimulus to other stimuli not correlated with reinforcement" (p. 131).

Thus in generalization, differences between stimuli are often assessed along the dimension correlated with reinforcement (Catania, 1992).

\section{Summary of the Literature Findings}

The literature has shown some consistency in illustrating the facilitative role of verbal behavior in rule-governing and rule-following behaviors. The interactions which exist between direct contingencies and verbal stimulus-controlled behavior have challenged behavior analysts to create methodological designs better suited to delineate the relationship between rule-governance, rule-following, and direct contingency-control behaviors. Although much has been accomplished during the last 25 years, there remain issues in the rule-following literature requiring further investigation. For example, although many studies have examined the extent to which verbal behavior affects participants' performances, few studies have systematically examined the extent to which verbal feedback, spoken to the participant listener after the completion of a series of 
tasks, affects the subsequent performances of this listener when other competing contingent relations are operating. In addition, the extent to which self-descriptions of such contingent-relations facilitates rule application in a generalization/transfer task needs to be further examined.

Thus, in expanding the work of Trigo et al. (1995) the present study had two main aims. The first aim was to investigate if participants, who were given the opportunity to describe verbally the contingent relations before the generalization test phase, produced a higher mean number of correct responses in this generalization phase compared to participants who were not given the opportunity to describe these relations. This thesis maintains that the verbal description of contingent relations influences the selective application of a rule. Thus, the correct description of the self-generated rule facilities the transfer of responses in subsequent "ambiguous" contexts. The second aim was to investigate the extent to which congruent, in contrast to incongruent, verbal feedback provided by an experimenter differentially affected the number of trials-to-criterion during a matching-to-sample conditional-discrimination training procedure. 


\section{Method}

\section{$\underline{\text { Participants }}$}

Eighty undergraduate college students recruited from psychology courses participated in this study. Students were asked to commit to making one visit to the laboratory, which involved approximately 60 minutes. For their participation, each student received extra credit towards their final grade in the course. The final sample consisted of 55 females and 25 males. Five additional participants were not included in the final sample, two because of a failure to meet criterion and three due to equipment failure. All participants signed an informed consent upon arrival and were debriefed upon completion of the study.

\section{Setting and Apparatus}

In the $3.5 \mathrm{~m} \times 3 \mathrm{~m}$ room, each subject was seated in a chair located at arms length from a computer equipped with a video monitor and an auditory stimulus generator. A $30 \times 32 \mathrm{~cm}$ computer screen displayed stimulus items consisting of two shapes (crosses and rectangles) each about 2 inches in height by 1 inch in length. For the first three phases, these two shapes were either red or green in color. For Phase 4 (the generalization-transfer test phase), a variety of new colors (including blue, white, yellow), in addition to red and green, were used. Also, for Phase 4 new shapes, in the form of 22 new stimulus figures, were presented in a range of new sizes (see Appendix $G$ for the Stimulus Figures). Pressing key No. 1 selected the stimulus figure located at the lower left corner of the screen while pressing key No. 2 selected the stimulus figure located at 
the lower right hand corner of the screen. The correct response, that is, selecting of either key No. 1 or No. 2, was scored automatically by the programmed computer.

\section{Design and Procedure}

A four Group X four Phases repeated-measures design was implemented.

The four phases were:

Phase 1 - In Phase 1, a sample stimulus, which appeared at the center of the screen, and the two comparison stimuli, one to the lower left and the other to the lower right, appeared concurrently on the screen. After a 3-sec exposure, a "flat" tone was introduced as an antecedent (discriminative) stimulus to signal the participant's selection of a comparison stimulus identical in color to the sample stimulus, regardless of stimulus shape. The correct response was immediately followed by a three-second duration of music, colorful lights, and shapes being flashed on the computer screen (to function as a reinforcer). This contingency was used also in Phases 2 and 3. A 3-sec inter-trial delay was programmed to reduce possible confounds between the set of stimulus figures in the preceding trial and the presentation of the tone in the new trial. The behavior criterion to complete Phase 1 was for participants to select 9 out of 12 correct responses.

Phase 2 - During Phase 2, the sample and comparison stimuli were presented concurrently, absent the tone, and the participant was required to match on identical shape, regardless of color. Correct responses were also followed as in Phase 1, by a 3-sec inter-trial delay. The behavior criterion for phase change in Phase 2 was 9 out of 12 correct matches. 
Phase $\underline{3}$ - Phase 3 involved conditional-discrimination training. The conditional relations presented in Phases 1 and 2 were mixed evenly, with the constraint that no more than three consecutive occurrences of the same condition be presented. Thus, the sample was alternated and the conditional discrimination could occur as a result of the participant's response to the two contingent relations. That is, selecting the stimulus comparison identical in color to the sample stimulus previously reinforced in the presence of a tone, and selecting a stimulus comparison identical in shape to the sample stimulus previously reinforced in the absence of the tone. The behavior criterion to complete Phase 3 , was 14 out of 16 correct responses.

Phase 4 - This phase involved testing for response transfer or generalization under extinction conditions. The putative discriminative sample stimuli consisted of novel colors, shapes and tones. No reinforcers were provided following the subject's correct choices. Thus, both correct and incorrect matches resulted in the presentation of the next trial. As in Phase 3, the participants were required to match on identical color when "any" stimulus tones were presented and to match on identical shape when these tones were absent. Phase 4, assessed for the generalization and transfer of training in the earlier phases and thus a fixed number $(\mathrm{N}=144)$ of trials was implemented for all participants.

The 80 participants were randomly assigned to one of the four groups $(\mathrm{N}=$ 20/group):

Group 1 - Participants received congruent verbal feedback (information consistent with the contingencies provided by the computer) from the experimenter 
across the three training phases of the experiment. For Group 1, at the end of each training phase, each participant was asked to describe verbally the correct responses in that phase. The experimenter provided positive feedback by saying, "Yes, that is correct" if the correct information was given by the participant and provided negative feedback by saying "No, that is not correct" if the participant described the incorrect choices. The experimenter's feedback statement, "That is partially correct," was given to participants in Group 1 who described partially-correct choices in Phase 3. Partially-correct choices were those that described only one of the two contingent relations.

Group 2 - Participants received incongruent verbal feedback from the experimenter (i.e., information conflicting with, or diametrically opposite to, the contingent relations provided by the computer) across the three training phases of the experiment. The feedback provided by the experimenter to participants in Group 2 was "No, that is not correct" if the participant described the correct choice, and "Yes, that is correct" if the participant described the incorrect choice. Participants in Group 2 who gave partially correct contingencies in Phase 3 were given incongruent feedback which targeted specific points of the choices described.

Group $\underline{3}$ - Participants in Group 3 were probed only at the end of Phase 3. That is, they were asked to describe in writing the contingent relations operating in Phases 1,2 and 3 before receiving the generalization test. No feedback was given by the experimenter. Computer feedback was given across the first three training phases.

Group 4 - Participants in Group 4 received no feedback from the experimenter 
and were not given the opportunity to describe the contingent relations at the end of Phases 1,2, and 3, before the final generalization test. Computer feedback was given across the first three training phases.

The presentations of Phases 1 and 2 were alternated among and within the four groups. At the beginning of Phase 1, participants were given the following set of instructions:

1) Please select one of the two stimuli at the bottom of the screen by pressing key No. 1 or key No. 2.

2) The lights, colors and music created by the computer indicates that you have made a correct selection. Next, try to figure out the response responsible for this correct selection. That is, what causes the lights, colors and music to appear.

3) There will be four phases in the entire experiment. When you hear a tone before the figures are presented, try to determine the role of this tone. That is, what was the correct selection when this tone was presented?

4) When you see a blank screen, it will indicate the end of each phase of the experiment. There will be four phases in the entire experiment. 


\section{Results}

The extent to which any differences in scores among participants may be attributed to experimenter's congruent or incongruent feedback was determined by comparing performances between Groups 1 and 2. The extent to which any differences in scores in the generalization test may be attributed to an opportunity some participants had to describe the contingent relations experienced in Phases 1,2, and 3 was determined by comparing performances between Groups 3 and 4. Two sets of statistical tests were chosen to evaluate the data. The first was a nonparametric Mann-Whitney $U$ test which was applied to the non-normally distributed trials-to-criterion data obtained in Phase 3. The second was a parametric one-tailed test which was applied to the normallydistributed numbers of correct-response data obtained in test Phase 4. In order to assume a normally distributed set of scores, 20 participants per group was chosen. Four questions were investigated:

Question 1: Did participants who received congruent verbal feedback from the experimenter differ in the number of trials-to-criterion from those participants who received incongruent verbal feedback from the experimenter? No significant differences between the number of trials-to-criterion of Group 1 and Group 2 in Phase $3(U=319, p$ $>.05)$ were obtained from the Mann-Whitney U test. Also, no significant differences between the scores of Groups 3 and 4 in Phase $3(U=374, p>.05)$ were obtained. 
Insert Figure 1 about here

Question 2: In Phase 4, did participants whose verbal descriptions received congruent feedback by the experimenter performed better in the generalization test than did those participants whose verbal descriptions received incongruent feedback? A onetailed $\underline{t}$ test between means was used to compare the performance between Group 1 and Group 2 in Phase 4. Results revealed that participants in Group $1(\mathrm{M}=74.65, \mathrm{SD}=$ 11.17), who had received verbal feedback congruent with computer-generated reinforcers, did not achieve a significantly higher number of correct responses $(\mathrm{t} 38=.59, \mathrm{p}>.10)$, than participants in Group 2, who received verbal feedback incongruent with the computer generated reinforcers $(\mathrm{M}=76.80, \mathrm{SD}=11.68)$.

Question 3: Did probing at the end of Phase 3, that is asking participants in Group 3 to describe what he/she did at the end of this training phase (using written reports), lead to a higher number of correct responses in test Phase 4, compared to participants in Group 4 who received no probing and had no opportunity to describe the contingent relations at the end of Phase 3? Participants in Group $3(\mathrm{M}=80.4, \mathrm{SD}=11.65)$, produced a significantly higher number of correct responses $(\mathrm{t} 38=2.22, \mathrm{p}<.05)$, than did participants in Group $4(\mathrm{M}=72.1, \mathrm{SD}=11.96)$. 
Insert Figure 2 about here

Question 4: Were participants who reached the learning criterion able to describe the two experimental contingent relations? Of the participants who attained criterion: In Group 1, 12 were able to describe the two contingent relations in the first three phases of the experiment; five participants in this group were unclear or stated only a part of the contingent relations in at least one of these three phases; and three were unable to state any of the two contingent relations. Of the participants attaining the learning criterion in Group 2, eight were able to describe the two contingent relations across the first three phases of the experiment; six were unclear or gave only partial contingent relations in at least one of these three phases; and six were unable to state any part of the contingent relations.

Insert Table 5 about here

Of the participants who had attained the learning criterion in Group 3, 14 were able to describe both contingent relations at the end of Phase 3; four were not clear or gave only partial contingencies at the end of this phase; while two could not state the relations. 
Insert Table 6 about here

Of the participants who had attained the learning criterion in Group 4, 12 were able to describe the contingencies at the end of Phase 4; six were not clear; while two could not state the relations.

Insert Figure 3 about here

Extinction Effects

To determine if the number of correct responses obtained in Phase 4 had been influenced by extinction, the number of correct responses in the first and last fifty trials were compared in Phase 4 for each participant. Results indicated no differences, suggesting that performances were homogeneous across trials in Phase 4 for all four groups. 


\section{Discussion}

\section{The Effects of Describing Contingent Relations}

The main findings in this study suggest that the participants' description of the contingent relations operating in a discrimination-training task facilitates rule-following in generalization tasks. That is, for participants in Group 3, the opportunity to describe these relations at the end of Phase 3, was associated with a higher number of correct responses in test Phase 4, compared to participants in Group 4 who had not been given this opportunity. Based on the criteria outlined by Ribes-Inesta et al. (1990), in test Phase 4 the novelty of stimulus items presented and the above-chance mean performance of the participants in Group 3, it is proposed that rule-governance was demonstrated by participants of this group. These results confirm the facilitative properties ascribed to self-generated rules in the literature (Trigo et al., 1995).

\section{The Effects of Experimenter's Congruent/Incongruent Verbal Feedback}

The results from Phase 3 indicated that the repeated incongruent verbal feedback provided by the experimenter did not significantly interfere with the performances of the participants of Group 2, compared to the participants of Group 1 who received repeated congruent verbal experimental feedback. Although such an outcome was not predicted, there is strong evidence which support the lack of differences between Groups 1 and 2 in this study. First, participants of Group 2 reported ignoring the verbal behavior of the experimenter in favor of the contingencies provided by the computer. The completion of the earlier two phases may serve to reinforce the matching behaviors of the participants in 
Group 2 and may have allowed these participants to obtain trial-to-criterion scores that were similar to participants in Group 1 in Phase 3. For example, Hayes, Brownstein, Haas and Greenway, (1986) and Hayes, Brownstein, Zettle, Rosenfarb and Korn, (1986) found that participants who had experienced a lack of correspondence between instructions (rules) and the experienced direct consequences eventually ignored these instructions in favor of the experienced direct contingencies. Second, when performances are shaped as a result of direct contingencies, subjects often become less sensitive to the verbal instructions (or verbal feedback) provided by the experimenter (Catania, Matthews, \& Shimoff, 1982). Thus, the results obtained in the current study are consistent with previous findings in the literature.

\section{Participants Verbal Description of Contingent Relations:}

\section{Group 1 versus Group 2}

In Group 1 (congruent), $60 \%$ of the participants were able describe correctly the two contingent relations they learned during the conditional-discrimination training, $25 \%$ were able to partially describe these relations, and $15 \%$ provided only incorrect descriptions. In contrast, Group 2 (incongruent) had $40 \%$ of the participants able to describe fully the two relations, $30 \%$ were partially able to describe these relations, and the remaining $30 \%$ provided only incorrect descriptions. These results suggest that, even though Groups 1 and 2 did not differ significantly in the number of trials-to-criterion on the conditional-discrimination task or on the mean number of correct responses in the generalization test, the congruent group was able to describe the "rule" specifying the 
contingent relations more readily than the incongruent group. Thus the incongruent feedback received by Group 2 could have interfered to a greater extent with the participants' verbal descriptions rather than with their actual performance. It is conceivable that a larger sample would have allowed the detection of significant statistical differences between these two groups.

In sum, the data suggest that a description of the contingencies does facilitate rulefollowing in a generalization task. However, the extent to which a rule is later applied seems to be influenced, on an average, by a verbal description of contingent relations prior to the generalization/transfer task at hand.

\section{Conclusion}

The present study contributes to the existing literature by expanding the work of Trigo et al. (1995) which examined rule performance and generalization in a matching-tosample task. Unlike the Trigo et al. (1995) study, however, the present study included a comparison group that neither received verbal feedback from the experimenter nor was given the opportunity to describe verbally their earlier performances. This procedure enabled a determination of the influence of such descriptions on subsequent performances. In addition, unlike the Trigo et al. (1995) study (which included a generalization test that was identical to their pretest) the present study included in its test phase auditory (i.e., tones) and visual (i.e., colors and shapes) stimuli that were different from those encountered in the training phases. Thus, due to the complexity and novelty of test Phase 4, it is argued that the present study expands upon the Trigo et al. (1995) 
previous findings in that response transfer (Catania, 1992) and rule-governance, rather than simple generalization and rule-following, were obtained for participants of Group 3. However, the extent to which response transfer and rule-governed behaviors obtained in this study is maintained in more radically different contexts needs to examined. This could be achieved by increasing the degree of "novelty" of the stimulus items in the test phase and by using three or more comparison stimuli in both the training and test phases. 


\section{References}

Bentall, R.P., Lowe, C.F., \& Beasty, A. (1985).The role of verbal behavior in human learning: II. Developmental differences. Journal of the Experimental Analysis of Behavior, $43,165-181$.

Buskist, W.F., \& Miller, H.L. (1986). Interaction between rules and contingencies in the control of human fixed-interval performance. Psychological Record, 36, 109-116.

Buskist, W. \& Johnston, J.M. (1988). Laboratory lore and research practices in the experimental analysis of human behavior. The Behavior Analyst, 11, 41-42.

Catania, A.C. (1992). Verbal learning and transfer. In A.C. Catania (Ed.), Learning (3rd ed.) (pp. 295-301). New Jersey: Prentice-Hall.

Catania, A.C., Matthews, B.A., \& Shimoff, E. (1982). Instructed versus shaped human verbal behavior: Interactions with nonverbal responding. Journal of the Experimental Analysis of Behavior, $\underline{38}, 233-248$.

Cerutti, D.T. (1989). Discrimination theory of rule- governed behavior. Journal of the Experimental Analysis of Behavior, 51, 259-276.

Critchfield, T.S., \& Perone, M. (1990). Verbal self- reports of delayed matching to sample by humans. Journal of the Experimental Analysis of Behavior, 53, 321-344.

Critchfield, T.S., \& Perone, M. (1993). Verbal self-reports about matching to sample: Effects of the number of elements in a compound sample stimulus. Journal of the Experimental Analysis of Behavior, 59, 193-214.

Dinsmoor, J.A. (1995a). Stimulus control: Part I. The Behavior Analyst, 18 , 
51-68.

Dinsmoor, J.A. (1995b). Stimulus control: Part II. The Behavior Analyst, 18, 253-269.

Galizio, M. (1987). Interpretation versus experimentation in the experimental analysis of human behavior. The Psychological Record, 37, 11-15.

Harzem, P., Lowe, C.F., \& Bagshaw, M. (1978). Verbal control in human operant behavior. The Psychological Record, 28,405-423.

Hayes, S.C., Brownstein, A.J., Zettle, R.D., Rosenfarb, I., \& Korn, Z. (1986).

Rule-governed behavior and sensitivity to changing consequences of responding. Journal of the Experimental Analysis of Behavior, 45, 237-256.

Hayes, S.C., Brownstein, A.J., Haas, J.R., \& Greenway D.E. (1986). Instructions, multiple schedule and extinction: Distinguishing rule-governed from scheduled-controlled behavior. Journal of the Experimental Analysis of Behavior, 46 , 137-147.

Hayes, S.C., \& Hayes, L.J. (1989). The verbal action of the listener as a basis for rule-governance. In S.C. Hayes (Ed.), Rule-governed behavior: Cognition, contingencies, and instructional control (pp. 153-190). New York: Plenum Press.

Hayes, S.C., \& Hayes, L.J. (1992). Verbal relations and the evolution of behavior analysis. American Psychologist, 47, 1383-1395.

Hayes, L.J., Thompson, S., \& Hayes, S.C. (1989). Stimulus equivalence and rule following. Journal of the Experimental Analysis of Behavior, 52, 275-291. 
Hayes, S.C., Zettle, R.B. \& Rosenfarb, I. (1989). Rule-following. In S.C. Hayes

(Ed.), Rule-governed behavior: Cognition, contingencies and instructional control, (p.204). New York: Plenum Press.

Horne P.J., \& Lowe C.F. (1993). On origins of naming and other symbolic behaviors. Journal of the Experimental Analysis of Behavior, $\underline{65}, 185-241$.

Leander, J.D., Lippman, L.G., \& Meyer, M.E. (1968). Fixed interval performance as related to subjects' verbalizations of the reinforcement contingency. The Psychological Record, 18, 469-474.

Lowe, C.F., Beasty, A., \& Bentall R.P. (1983). The role of verbal behavior in human learning: Infant performance on fixed-interval schedules. Journal of the Experimental Analysis of Behavior, $\underline{39}, 157-164$.

Michael, J. (1984). Verbal behavior. Journal of the Experimental Analysis of Behavior, 42, 363-376.

Parrott, L.J., (1987). Rule-governed behavior: An implicit analysis of reference. In S. Modgil \& C. Modgil (Eds.), B.F. Skinner: Consensus and Controversy (pp. 265276). Sussex, England: Falmer Press.

Pelaez-Nogueras, M., \& Gewirtz, J.L. (1995). The learning of moral behavior: A behavior analytic approach. In W.M. Kurtines \& J.L. Gewirtz (Eds.), Moral behavior: An introduction, (pp. 173-199). Boston: Allyn \& Bacon.

Perone, M. (1988). Laboratory lore and research practices in the experimental analysis of behavior: Use and abuse of subjects' verbal reports. The Behavior Analyst, 11 , 
$71-75$.

Pilgrim, C., \& Johnston, J.M. (1988). Laboratory lore and research practices in the experimental analysis of human behavior: Issues in instructing subjects. The Behavior Analyst, 11, 59-64.

Pouthas, V., Droit, S., Jacquet, A.-Y., \& Weardon, J.H. (1990). Temporal differentiation of response duration in children of different ages: Developmental changes in relations between verbal and nonverbal behavior. Journal of the Experimental Analysis of Behavior, 53, 21-31.

Ribes-Inesta, E., \& Martinez-Sanchez, H. (1990). Interaction of contingencies and rule instructions in the performance of human subjects in conditional discrimination. The Psychological Record, 40, 565-586.

Schlinger, H.D., \& Blakely, E. (1987). Function-altering effects of contingency-specifying stimuli. The Behavior Analyst, 10, 41-45.

Schlinger, H.D. (1993). Separating discriminative and functioning-altering effects of verbal stimuli. The Behavior Analyst, 16, 9-23.

Shimoff, E., Matthews, B.A., \& Catania, A.C. (1986). Human operant performance: Sensitivity and Pseudosensitivity to contingencies. Journal of the Experimental Analysis of Behavior, $\underline{46}, 149-157$.

Skinner, B.F. (1957). Verbal behavior. New York: Appelton-Century-Crofts.

Skinner, B.F. (1966). An operant analysis of problem solving. In B. Kleinmuntz (Ed.), Problem solving: Research, method, and theory. (225-257). New York: Wiley. 
Skinner, B.F. (1984). An operant analysis of problem solving. Behavioral and Brain Sciences, 7, 583-613.

Trigo, E., Martinez-Sanchez, R., \& Moreno R. (1995). Rule performance and generalization in a matching-to-sample task. The Psychological Record, 45, 223-240.

Vaughan, M.E. (1985). Repeated acquisition in the analysis of rule-governed behavior. Journal of the Experimental Analysis of Behavior, 44, 175-184.

Vaughan, M.E. (1989). Rule-governed behavior in behavior analysis. In S.C. Hayes (Ed.), Rule-governed behavior. New York: Plenum Press.

Weiner, H.(1964). Conditioning history and human fixed-interval performance. Journal of the Experimental Analysis of Behavior, 1, 383-385.

Weiner, H. (1969). Controlling human fixed-interval performance. Journal of the Experimental Analysis of Behavior, 12, 349-373.

Zettle, R.D. (1990). Rule-governed behavior: A radical behavioral answer to the cognitive challenge. The Psychological Record, 40, 41-49. 


\section{List of Figures}

Stimulus figures used in the matching-to-sample conditional-discrimination training (Phases 1, $2 \& 3$ ) and generalization/transfer test phase (Phase 4).

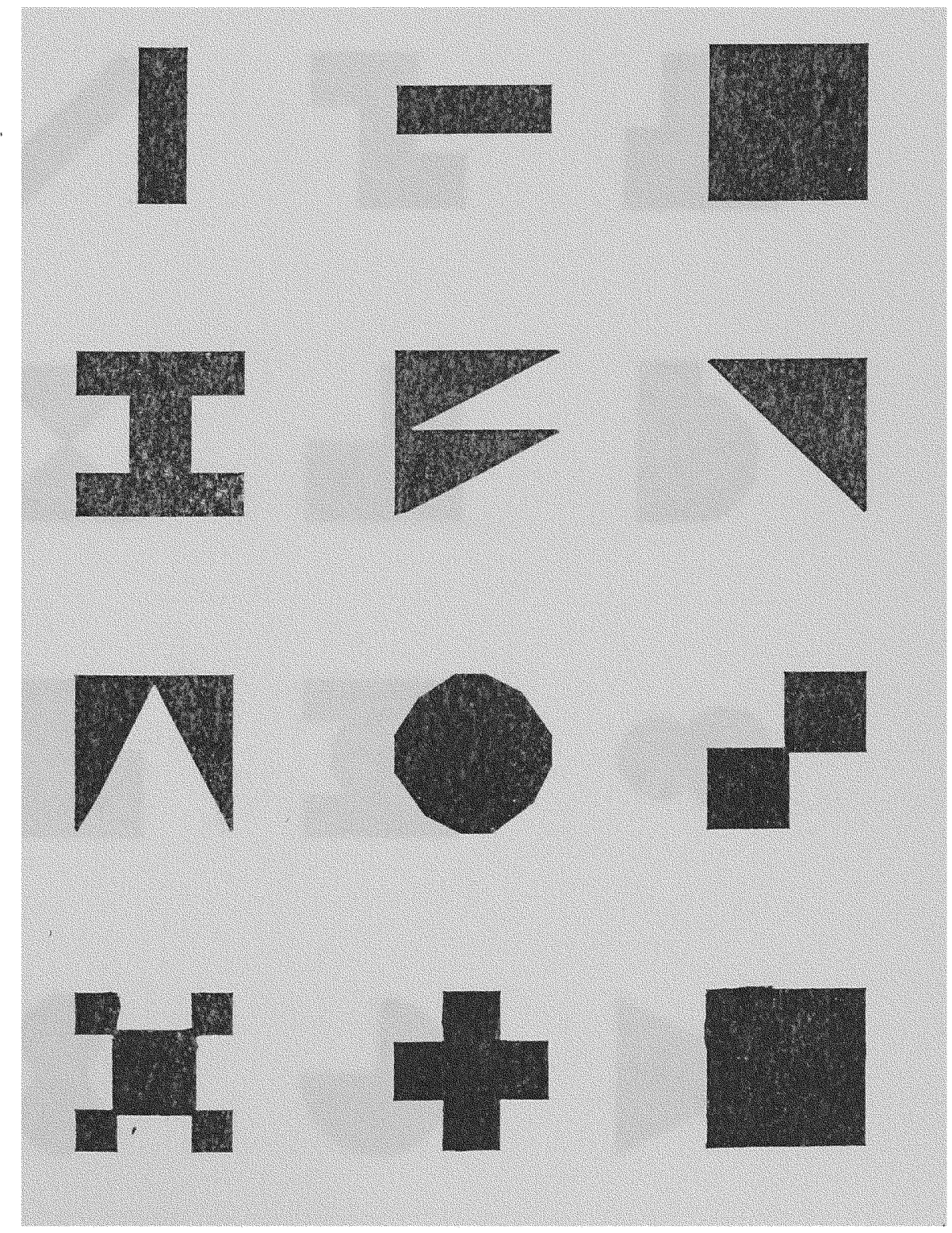


STIMULUS ITEMS

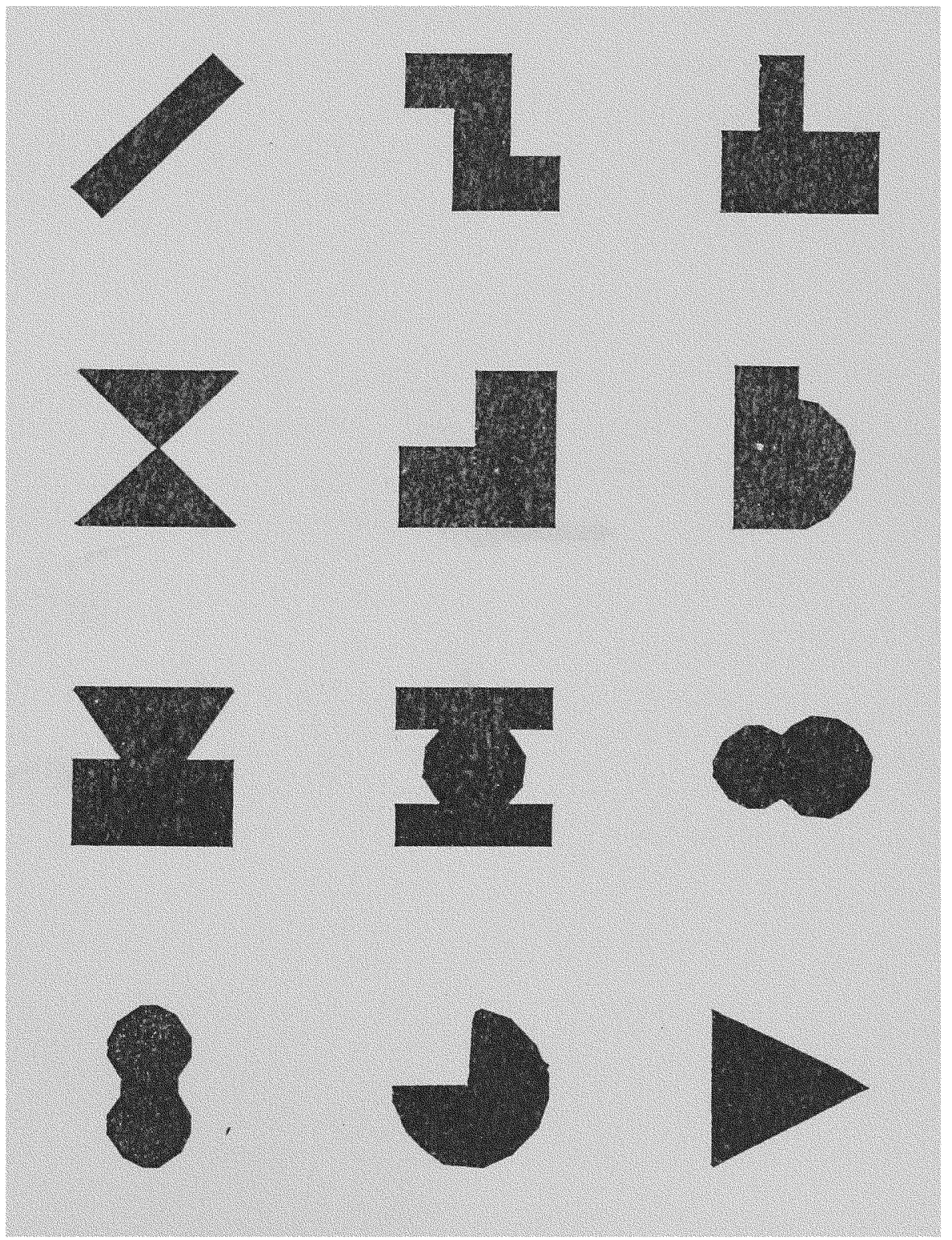


-Appendices- 
Appendix A 
Table 1: Raw Data - Group 1.

Table 2: Raw Data - Group 2.

Table 3: Raw Data - Group 3.

Table 4: Raw Data - Group 4.

Tables 1-4 show the number of trails-to-criterion in Phases 1,2 and 3 , plus the number of correct trials for phase 4 for each group. 
Table 1.

\section{RAW DATA}

GROUP 1

Number of Trials to Criterion

Rhase 1.

\section{S\#}

1. 15

2. 13

3. 22

4. 12

5. 46

6. 15

7.149

8. 23

9. 13

10. 12

11. 21

12. 14

13. 13

14. 63

15. 62

16. 21

17. 17

18. 13

19. 12

20. 26
Rhase 2.

13

13

14

13

16

13

12

12

12

13

37

12

12

32

97

12

12

12

12

93
18

321

105

46

136

366

61

220

16

19

39

81

16

18

179

35

17

81

61

222
Number of Trials with Correct Responses $(\mathrm{N}=144$ Trials $)$ Phase 4. \begin{tabular}{l|c|} 
Tot: 582 & 462 \\
\hline
\end{tabular}

Mean Number of Trials to Criterion
$97=67.0 \%$

$56=38.9 \%$

$57=39.6 \%$

$80=55.6 \%$

$69=47.9 \%$

$67=46.5 \%$

$75=52.1 \%$

$68=47.2 \%$

$82=56.9 \%$

$71=49.3 \%$

$84=58.3 \%$

$64=44.4 \%$

$72=50.0 \%$

$81=56.3 \%$

$68=47.2 \%$

$93=64.6 \%$

$86=59.7 \%$

$84=58.3 \%$

$63=43.8 \%$

$76=52.8 \%$
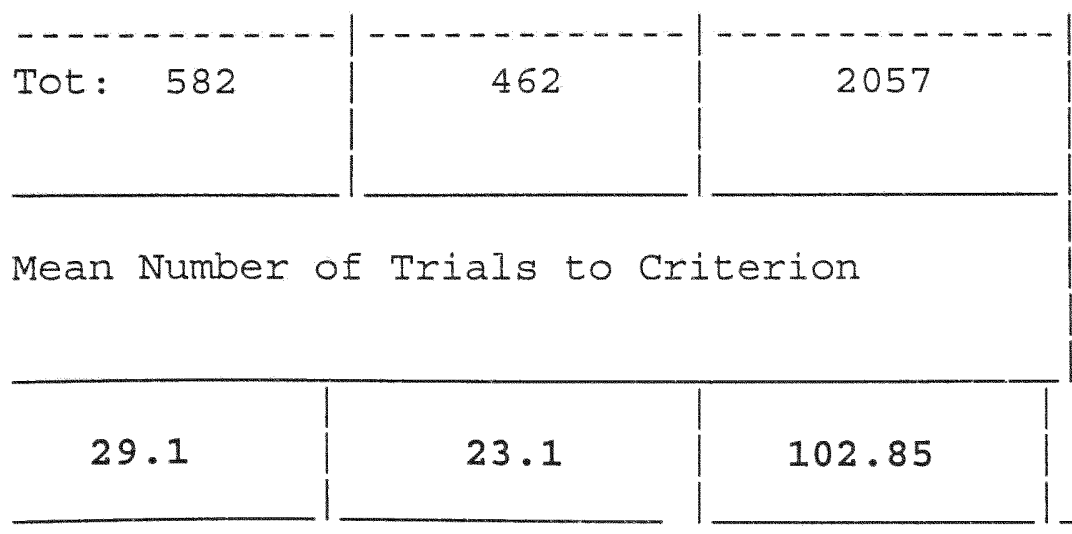

Mean Number of

Correct Responses + Mean Percentage

102.85

$74.6 / 51.84 \%$ 
Table 2.

RAW DATA.

\section{GROUP 2}

Trials

| Number of

Number of Trials to Criterion

with Correct Responses $(N=144$

Trials)

Phase 1. Phase 2. Phase 3.

Phase 4.

$\mathrm{SH}$

1. 43

43

91

2. 13

13

3. 12

14

4. 15

12

5. 69

12

6. 13

12

7. 41

13

8. $\quad 12$

24

9. 13

30

10. 13

23

11. 13

12

12. 28

36

13. 42

16

14. 16

13

15. 14

14

16. 15

13

17. 12

15

18. 18

14

19. 44

36

20. 13

14

318

283

17

16

254

300

38

80

48

18

36

35

112

103

18

37

91

448

500

234
$72=50.0 \%$

$71=49.3 \%$

$71=49.3 \%$

$80=55.6 \%$

$97=67.4 \%$

$63=43.8 \%$

$79=54.9 \%$

$72=50.0 \%$

$75=52.1 \%$

$68=47.2 \%$

$78=54.2 \%$

$66=45.8 \%$

$105=72.9 \%$

$68=47.2 \%$

$82=56.98$

$78=54.2 \%$

$78=54.2 \%$

$69=47.9 \%$

$100=69.4 \%$

$64=44.4 \%$

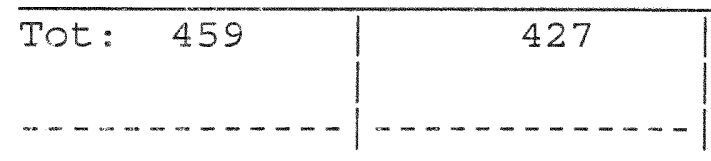

Mean Number of Trials to Criterion

$\mid \begin{gathered}2986 \\ \ldots \ldots \ldots\end{gathered}$

1536

Mean Number of

Correct Responses $1+$ Mean Percentage

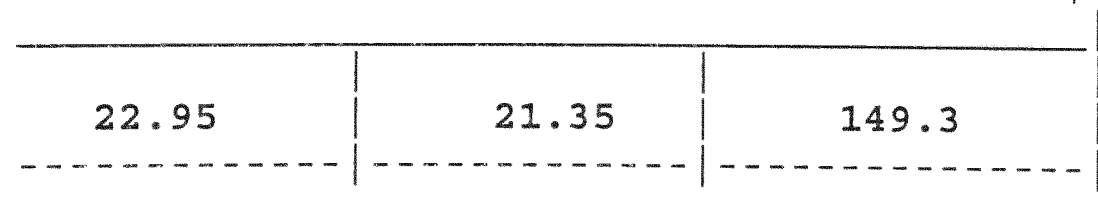

$76.8 / 53.33 \%$ 
Table 3

RAW DATA.

GROUP 3

Number of Trials to Criterion

Phase $1 . \quad$ Phase 2.
Phase 3 .
Number of Trials with Correct Responses $(N=144$ Trials $)$

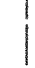

Phase 4.

\section{S\#}

1 .

2.

21

1.3

15

3.

4.

5.

55

81

6.

12

7.

17

8.

24

9.14

10. 24

11. 12

12. 12

13. 14

14. 12

15. 12

16. 26

17. 22

18. 13

19. 28

20. 14
12

15

13

250

26

12

20

13

14

15

12

15

12

13

13

21

13

49

12

12
343

262

177

278

320

58

312

37

17

109

41

36

35

59

40

182

216

17

41

35
$85=59.0 \%$

$69=47.9 \%$

$78=54.2 \%$

$75=52.1 \%$

$73=50.7 \%$

$99=68.8 \%$

$65=45.1 \%$

$98=68.18$

$66=45.8 \%$

$71=49.3 \%$

$101=70.1 \%$

$79=54.98$

$90=62.5 \%$

$78=54.2 \%$

$77=53.5 \%$

$70=4.8 .6 \%$

$66=45.8 \%$

$93=64.6 \%$

$83=57.6 \%$

$92=63.9 \%$

\begin{tabular}{l|c|c|}
\hline & & \\
Tot: & 441 & 562 \\
\hline$-\ldots-\ldots$ & $-\ldots-\ldots$
\end{tabular}

$\left|\begin{array}{c}2615 \\ -\ldots-\ldots-\ldots\end{array}\right|$

Mean Number of Trials to Criterion
1608

Mean Numoer of Correct Responses $1+$ Mean Percentage -

130.75 
Table 4.

RAW DAIA.

GROUP 4

Number of Trials to Criterion

Phase 1.

\section{S\#}

1. 13

2. 24

3. 12

4. 16

5. 16

6. 15

7. 41

8. 13

9. 45

10. 12

11. 75

12. 82

13. 13

14. 74

15. 12

16. 46

17. 14

18. 76

19. 15

20. 14

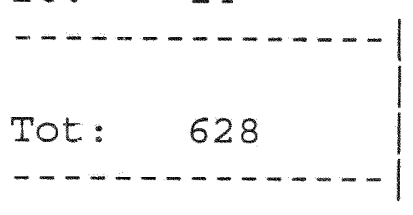

Number of

Mean Number of Trials to Criterion
16

18

273

17

159

297

88

227

134

16

35

17

38

413

18

351

297

17

383

134

Number of Trials with Correct

Responses 40 $(N=144$ Trials $)$

Phase 4.

$71=49.3 \%$

$87=60.0 \%$

$71=49.3 \%$

$70=48.6 \%$

$94=65.3 \%$

$81=56.6 \%$

$73=50.7 \%$

$61=42.4 \%$

$88=61 \cdot 1 \%$

$67=46.5 \%$

$60=41.5 \%$

$69=47.9 \%$

$52=36.1 \%$

$85=57.6 \%$

$50=34.7 \%$

$64=44.4 \%$

$72=50.0 \%$

$89=61.8 \%$

$69=47.9 \%$

$71=49.3 \%$
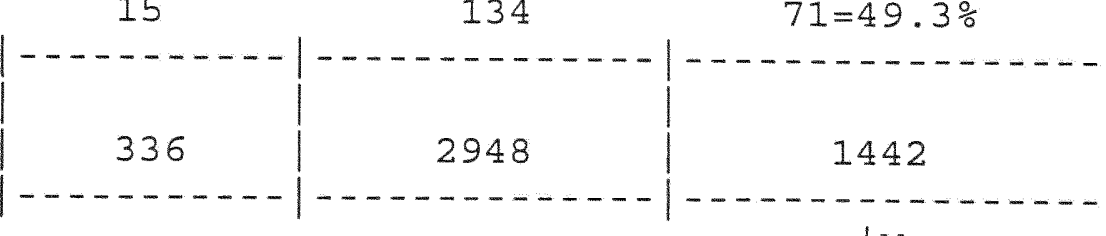

| Mean

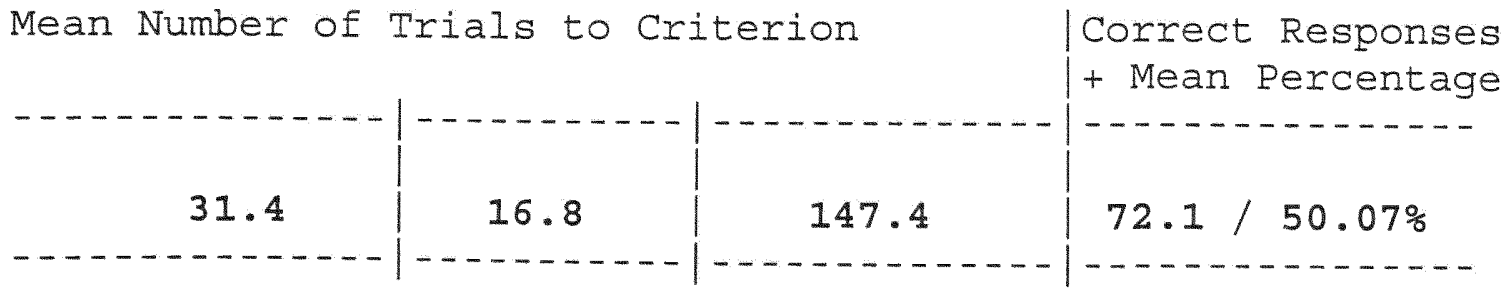


Grand means for all four phases:

Phase 1: 582

459

441

628

$2,110 / 80=26.375$

Phase 2: 462

427

562

336

$1,787 / 80=22.3375$

Phase 3: 2057

2986

2615

2948

$10,606 / 80=132.575$

Phase 4: 1493

1536

1608

1442

$6,079 / 80=75.9875 / 144=52.77 \%$ approx. $53 \%$

Grand mean for Phase 4 is 75.99 correct out of 144 trials, (or 53웅 correct).

Total Responses per group:

Group 1 -.. 3101 (total) ave. resp. = 155

Group 2 -.-3872 (total) ave. resp. = 194

Group 3 ---3618 (total) ave. resp. = 181

Group 4 -..-3912 (total) ave. resp. = 196 
Table 5 .

Ordering within Groups 1 and 2: Based on Subject's Description of contingent Relations in Phases 1 , 2 , and 3 plus Generalization Performance in Phase 4.

Key (For Tables $5 \& 6$ ).

sc - stated the two contingent relations

pc - stated one of the two contingent relations)

nc - not able to state neither of the two contingent relations

$\mathrm{P} 1$ = Phase 1; $\mathrm{P} 2$ = Phase 2; $\mathrm{P} 3$ = Phase $3 ; \mathrm{P} 4=$ Phase 4 S\# - subject number within each group

Grand mean for Phase 4 (Generalization Phase) was 76 correct responses out of 144 trials (or 53\% correct).

$\mathrm{y}=$ yes (scored above grand mean); $\mathrm{n}=$ no (did not score above grand mean)

\begin{tabular}{lll|l|ll|l} 
Group 1 & scored above & Group & & Scored above \\
Grand Mean & & & & \\
Grand Mean
\end{tabular}


Table 6 .

Ordering: Based on Subject's Description of the two

Contingent Relations at the end of Phase 3 for Group 3 and during Debriefing for Group 4

Group 3

P3

1. rule pc

2. rule

3. rule pc

4. rule nc

5. rule pc

6. rule

7. rule

8. rule

9. rule

10. rule

11. rule

12. rule

13. rule

14. rule

15. rule

16. rule pc

17. rule nc

18. rule

19. rule

20. rule
Scored above

Grand Mean

Y

n

Y

$n$

n

Y

n.

y

n

n

Y

Y

Y

Y

Y

n

n

y

$Y$

Y
Group 4

P3

rule

rule

rule nc

rule

rule

rule

rule pc

rule nc

rule

rule

rule pc

rule

rule

rule pc

rule pc

rule

rule

rule

rule pc

rule pc
Scored above

Grand Mean n

y

n

n

y

y

n

n

Y

n

n

n

n

$y$

n

n

n

y

n

$n$ 
Summary of Generalization/Transfer Performance using Grand Mean Comparison of $53 \%$ correct in Test Phase 4

Group 1 - 40\% of the subjects in this group gen./transfer. Group 2 - 45\% of the subjects in this group gen./transfer. Group 3 - 60\% of the subjects in this group gen./transfer. Group 4 - 30\% of the subjects in this group gen./transfer. 


\section{$t$ test}

Groups: 3 and 4

Phase: 4

Assumptions (justification): Homogeneous variances, normal distribution of sample, random sampling from population.

Mean for Group 3 is 80.4 ; where Group 3 is the treatment group.

Mean for Group 4 is 72.1 ; where Group 4 is the control group.

Two Tailed T-test for independent Sample

$$
t=\frac{M_{t}-M_{c}}{\text { Smt-mc }}
$$

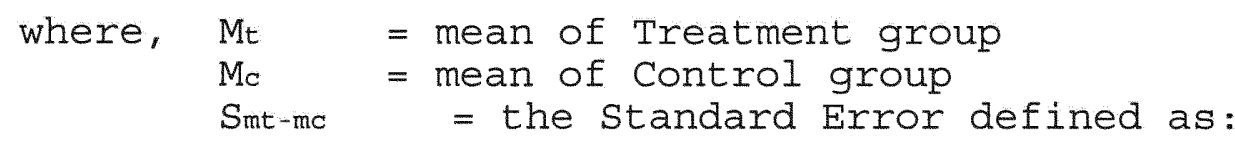

Smt-mc
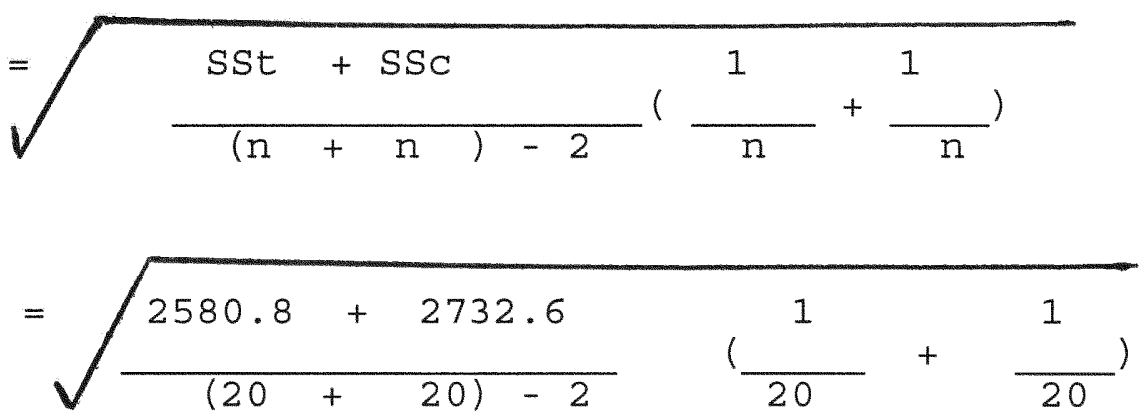

$=\sqrt{\left(\frac{5313.4}{38}\right)(0.1)}$

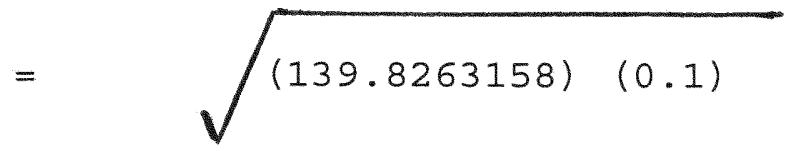




$\begin{array}{ll} & =\frac{\sqrt{13.98263158}}{\text { Smt-mc }}= \\ t \quad= & \frac{80.739335714}{3.739335714} \\ t \quad & =\frac{8.3}{3.739335714} \\ t & =2.219645583\end{array}$

Rejection Region at 38 degrees of freedom, at alpha $=.05$.

This is between critical values

$$
\begin{aligned}
& 30 \text { degrees }=2.042 \\
& 40 \text { degrees }=2.021
\end{aligned}
$$

Hence at $t=2.220$, we have significance. There is sufficient evidence to indicate that these two populations are different at alpha $=.05$. (Reject Ho). 
Table 7.

Group 3 (SSt)

1. $85 \sim 21.16$

2. $69 \sim 129.96$

3. $78 \sim 5.76$

4. $75 \sim 29.16$

5. $73 \sim 54.76$

6. $99 \sim 345.96$

7. $65 \sim 237.16$

8. $98 \sim 309.76$

9. $66 \sim 207.36$

10. $71 \sim 88.36$

11. $101 \sim 424.36$

12. $79 \sim 1.96$

13. $90 \sim 92.16$

$14.78 \sim 5.76$

$15.77 \sim 11.56$

16. $70 \sim 108.16$

17. $66 \sim 207.36$

18. $93 \sim 158.76$

19. $83 \sim 6.76$

$20.92 \sim 134.56$

Total 2580.80
Group 4 (SSC)

1) $71 \sim 0.09$

2) $87 \sim 246.49$

3) $55 \sim 265.69$

4) $70 \sim 1.69$

5) $94 \sim 515.29$

6) $81 \sim 94.09$

7) $73 \sim 2.89$

8) $61 \sim 106.09$

9) $88 \sim 278.89$

10) $67 \sim 18.49$

11) $60 \sim 127.69$

12) $69 \sim 5.29$

13) $52 \sim 372.49$

14) $83 \sim 136.89$

15) $50 \sim 453.69$

16) $64 \sim 53.29$

17) $72 \sim 0.49$

18) $89 \sim 313.29$

19) $69 \sim 5.29$

20) $71 \sim 0.09$

Total 2998.20 


\section{t test}

Groups 1 and 2

Phase 4

Mean for Group 1 is 74.65

Mean for Group 2 is 76.8

For Group $1 \mathrm{SSC}=2372.55$

For Group 2 sSt $=2591.2$

No significant difference in the scores between these two groups were obtained. 


\section{Mann-Whitney U test}

$$
\begin{aligned}
& \mathrm{Ua}=\mathrm{n} \mathrm{n}+\frac{\mathrm{n}(\mathrm{n}+1)-\mathrm{R}}{2} \\
& \mathrm{Ub}=\mathrm{n} \mathrm{n}+\frac{\mathrm{n}(\mathrm{n}+1)-\mathrm{R}}{2}
\end{aligned}
$$

Where,

$\mathrm{n}=$ the number of subjects in Group a (Group 1)

$n$ = the number of subjects in Group $b$ (Group 2)

$\mathrm{Ra}$ and $\mathrm{Rb}$ are the sums of the ranks for Groups $\mathrm{a}$ and $\mathrm{b}$, respectively. 
Table 8 .

Ranks between Groups 1 and 2 for Phase 3 .

Subject (\# for each Group)

\begin{tabular}{|c|c|c|c|c|}
\hline 1 & 18 & (1) & 318 & (2) \\
\hline 2 & 321 & (1) & 283 & (2) \\
\hline 3 & 105 & (1) & 17 & (2) \\
\hline 4 & 46 & (1) & 16 & (2) \\
\hline 5 & 136 & (1) & 254 & (2) \\
\hline 6 & 366 & (1) & 300 & (2) \\
\hline 7 & 61 & (1) & 38 & (2) \\
\hline 8 & 220 & (1) & 80 & (2) \\
\hline 9 & 16 & (1) & 48 & (2) \\
\hline 10 & 19 & (1) & 18 & (2) \\
\hline 11 & 39 & (1) & 36 & (2) \\
\hline 12 & 81 & (1) & 35 & (2) \\
\hline 13 & 16 & (1) & 112 & (2) \\
\hline 14 & 18 & (1) & 103 & (2) \\
\hline 15 & 179 & (1) & 18 & (2) \\
\hline 16 & 35 & (1) & 37 & (2) \\
\hline 17 & 17 & (1) & 91 & (2) \\
\hline 18 & 81 & (1) & 448 & (2) \\
\hline 19 & 61 & (1) & 500 & (2) \\
\hline 20 & 222 & (1) & 234 & (2) \\
\hline
\end{tabular}

Scores and Groups

(2) 
Table 2.

\begin{tabular}{|c|c|c|}
\hline Group 1 Ranks & Group & 2 Ranks \\
\hline 1 & & 1 \\
\hline 2 & & 2 \\
\hline 3 & & 3 \\
\hline 4 & & \\
\hline 5 & & 5 \\
\hline & & 6 \\
\hline & & 7 \\
\hline 9 & & 8 \\
\hline 10 & & \\
\hline & & 11 \\
\hline 12 & & 12 \\
\hline 14 & & Ju \\
\hline & & 15 \\
\hline 17 & & \\
\hline & & 18 \\
\hline $\begin{array}{l}19 \\
20\end{array}$ & & \\
\hline $\begin{array}{l}20 \\
21\end{array}$ & & \\
\hline $\begin{array}{l}21 \\
22\end{array}$ & & \\
\hline 84 & & 23 \\
\hline & & 24 \\
\hline & & 25 \\
\hline & & 26 \\
\hline & & 27 \\
\hline 29 & & \\
\hline & & 30 \\
\hline & & 31 \\
\hline
\end{tabular}


Table 10.

Ranks between Groups $\underline{3}$ and $\underline{4}$ for Phase 3 .

Subject (\# for each Group)

1

2

3

4

5

6

7

8

9

10

11

12

13

14

15

16

17

18

19

20
Scores and Groups

$\begin{array}{rrrr}343 & (3) & 16 & (4) \\ 262 & (3) & 18 & (4) \\ 177 & (3) & 273 & (4) \\ 278 & (3) & 17 & (4) \\ 320 & (3) & 159 & (4) \\ 58 & (3) & 297 & (4) \\ 312 & (3) & 88 & (4) \\ 37 & (3) & 227 & (4) \\ 17 & (3) & 134 & (4) \\ 109 & (3) & 16 & (4) \\ 41 & (3) & 35 & (4) \\ 36 & (3) & 17 & (4) \\ 35 & (3) & 38 & (4) \\ 59 & (3) & 413 & (4) \\ 40 & (3) & 18 & (4) \\ 182 & (3) & 351 & (4) \\ 216 & (3) & 297 & (4) \\ 17 & (3) & 17 & (4) \\ 41 & (3) & 383 & (4) \\ 35 & (3) & 134 & (4) \\ & (3)\end{array}$


Table 11.

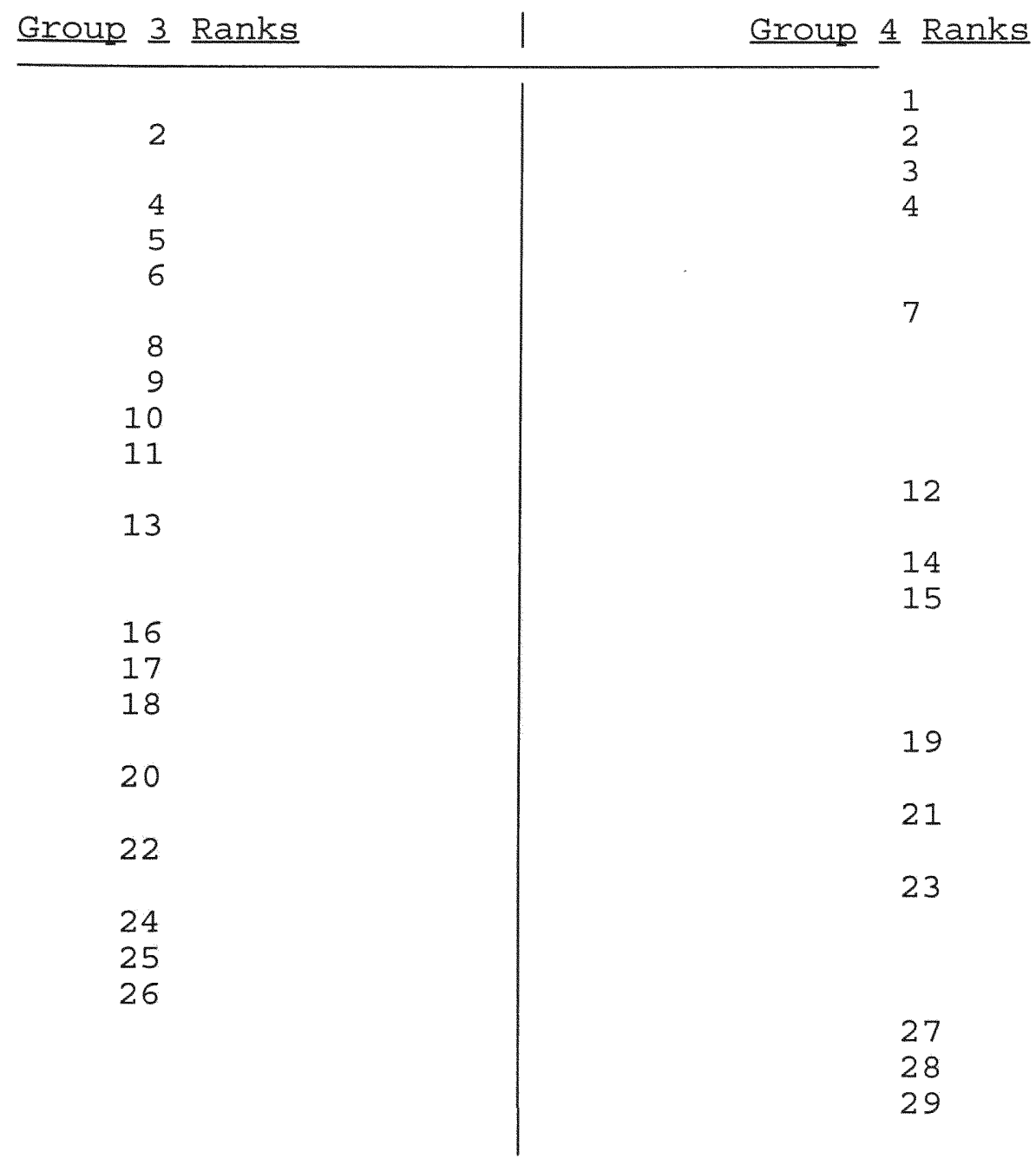


Table 12.

Group 1

\section{Extinction Effects in Phase 4.}

Number/Percent

Correct

Total-144 Trials

\section{Number/Percent} Correct -First 50 Trials

\section{Number/Percent} Correct

-Last 50 Trials
S\#

1. $97=67 \%$

2. $56=39 \%$

3. $57=40 \%$

4. $80=56 \%$

5. $69=48 \%$

6. $67=47 \%$

7. $75=52 \%$

8. $68=47 \%$

9. $82=57 \%$

10. $71=49 \%$

11. $84=58 \%$

12. $64=44 \%$

13. $72=50 \%$

14. $81=56 \%$

15. $68=47 \%$

16. $93=65 \%$

17. $86=60 \%$

18. $84=58 \%$

19. $63=44 \%$

20. $76=53 \%$

Ave: $75=52 \%$
$32=64 \%$

$24=48 \%$

$21=42 \%$

$26=52 \%$

$24=48 \%$

$21=42 \%$

$28=56 \%$

$23=46 \%$

$20=40 \%$

$31=62 \%$

$29=58 \%$

$23=46 \%$

$24=48 \%$

$29=58 \%$

$26=52 \%$

$27=54 \%$

$29=58 \%$

$23=46 \%$

$25=50 \%$

$27=54 \%$

$26=52 \%$
$34=68 \%$

$21=42 \%$

$19=38 \%$

$29=58 \%$

$24=48 \%$

$25=50 \%$

$28=56 \%$

$26=52 \%$

$36=72 \%$

$23=46 \%$

$31=62 \%$

$20=40 \%$

$25=50 \%$

$28=56 \%$

$22=44 \%$

$40=80 \%$

$28=56 \%$

$34=68 \%$

$19=38 \%$

$29=58 \%$

$27=54 \%$ 
Table 13.

Group 2

Extinction Effects in Phase 4

Number/Percent Correct

Total-144 Trials

$\mathrm{S \#}$

1. $72=50 \%$

2. $71=49 \%$

3. $71=49 \%$

4. $80=56 \%$

5. $\quad 97=67 \%$

6. $63=44 \%$

7. $\quad 79=55 \%$

8. $72=50 \%$

9. $75=52 \%$

10. $68=47 \%$

11. $78=54 \%$

12. $66=46 \%$

13. $105=73 \%$

14. $68=47 \%$

15. $82=57 \%$

16. $78=54 \%$

17. $78=54 \%$

18. $69=48 \%$

19. $100=69 \%$

20. $64=44 \%$

**Ave: $\quad 77=53 \%$
Number/Percent Correct -First 50 Trials
Number/Percent Correct -Last 50 Trials
$25=50 \%$

$28=56 \%$

$25=50 \%$

$26=52 \%$

$33=66 \%$

$21=42 \%$

$27=54 \%$

$29=58 \%$

$23=46 \%$

$25=50 \%$

$26=52 \%$

$28=56 \%$

$26=52 \%$

$24=48 \%$

$26=52 \%$

$29=58 \%$

$27=54 \%$

$22=44 \%$

$34=68 \%$

$27=54 \%$

$27=54 \%$
$23=46 \%$

$20=40 \%$

$25=50 \%$

$28=56 \%$

$35=70 \%$

$22=44 \%$

$26=52 \%$

$20=40 \%$

$25=50 \%$

$24=48 \%$

$28=56 \%$

$22=44 \%$

$46=92 \%$

$23=46 \%$

$35=70 \%$

$27=54 \%$

$30=60 \%$

$24=48 \%$

$35=70 \%$

$20=40 \%$

$27=54 \%$ 
Table 14.

Group 3

Extinction Effects in Phase 4

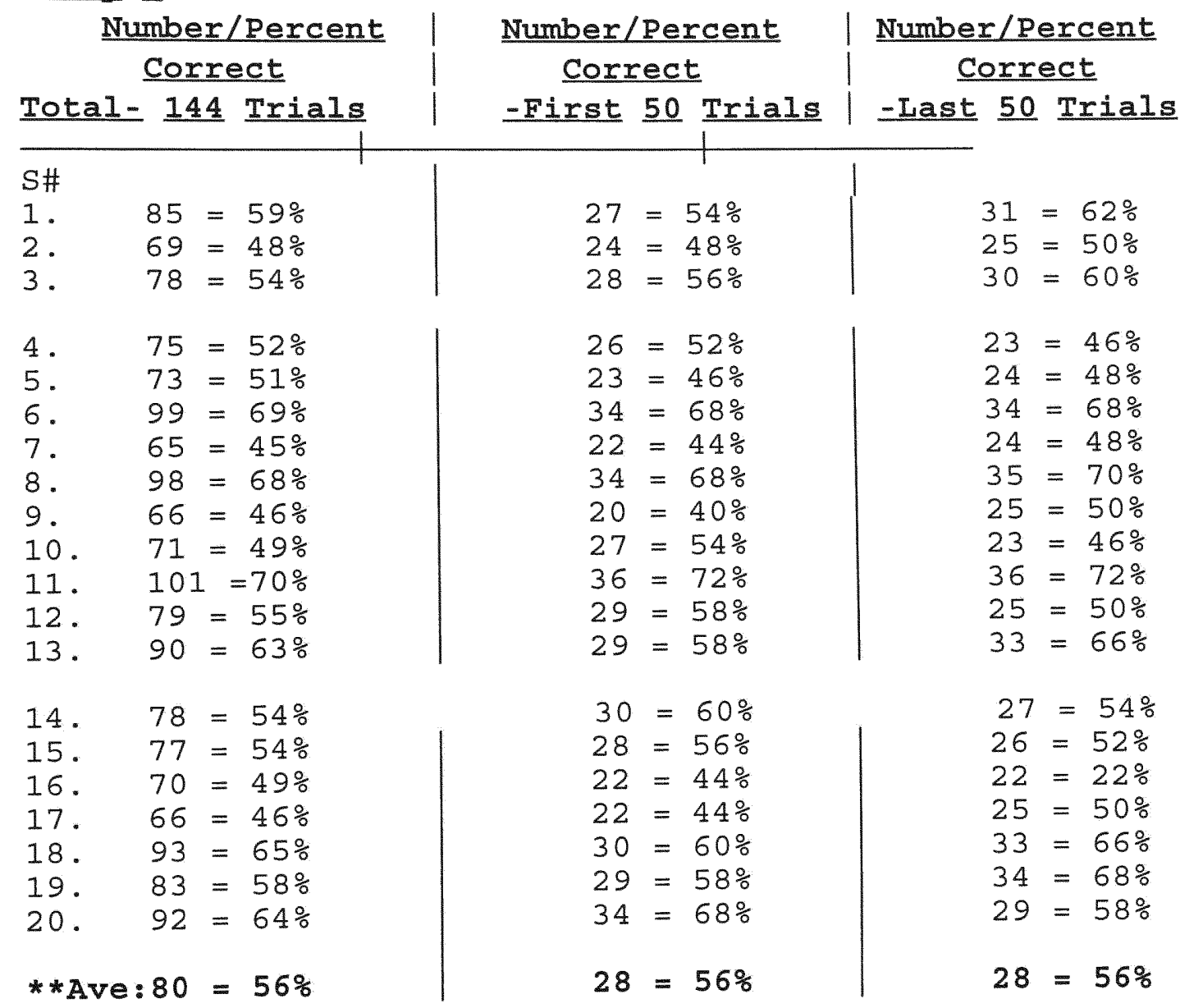


Table 15.

Group 4

Extinction Effects in Phase 4

Number/Percent

Correct

Total- 144 Trials
Number/Percent

Correct

-First 50 Trials
Number/Percent Correct -Last 50 Trials
S\#

1. $\quad 71=49 \%$

2. $87=60 \%$

3. $\quad 71=50 \%$

4. $70=49 \%$

5. $\quad 94=65 \%$

6. $81=57 \%$

7. $\quad 73=51 \%$

8. $61=42 \%$

9. $88=61 \%$

10. $67=47 \%$

11. $60=42 \%$

12. $69=48 \%$

13. $52=36 \%$

14. $83=58 \%$

15. $50=35 \%$

16. $64=44 \%$

17. $72=50 \%$

18. $89=62 \%$

19. $69=48 \%$

20. $71=49 \%$

**Ave: $72=50 \%$
$27=54 \%$

$24=48 \%$

$22=44 \%$

$28=56 \%$

$30=60 \%$

$26=52 \%$

$25=50 \%$

$19=38 \%$

$33=66 \%$

$23=46 \%$

$20=40 \%$

$23=46 \%$

$15=30 \%$

$27=54 \%$

$20=40 \%$

$27=54 \%$

$28=56 \%$

$34=68 \%$

$19=38 \%$

$25=50 \%$

$25=50 \%$
$28=56 \%$

$35=70 \%$

$27=54 \%$

$21=42 \%$

$34=68 \%$

$29=58 \%$

$28=56 \%$

$25=50 \%$

$25=50 \%$

$23=46 \%$

$22=44 \%$

$25=50 \%$

$17=34 \%$

$31=62 \%$

$17=34 \%$

$21=42 \%$

$29=58 \%$

$26=52 \%$

$29=58 \%$

$22=44 \%$

$26=52 \%$ 
Appendix B 


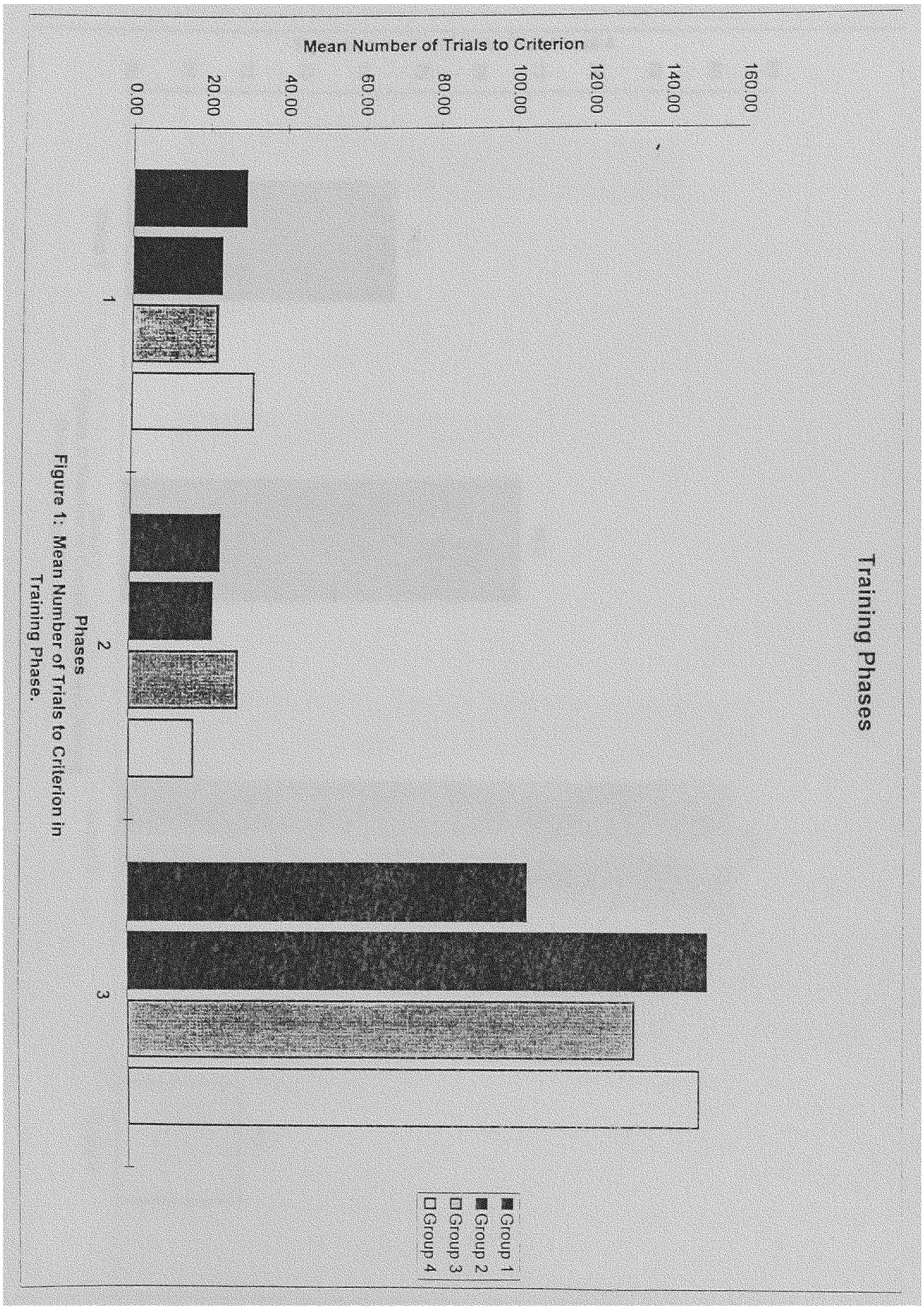




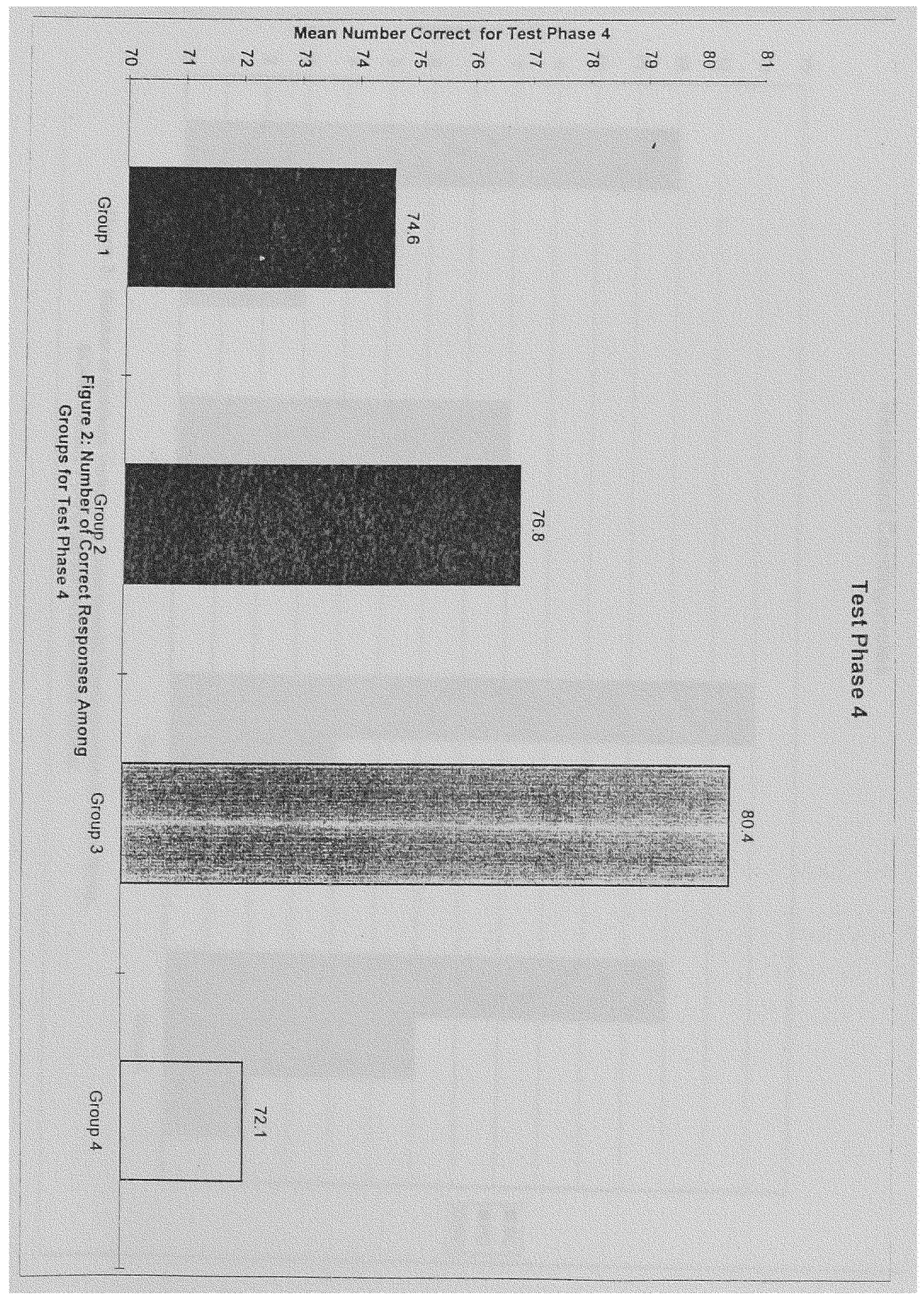




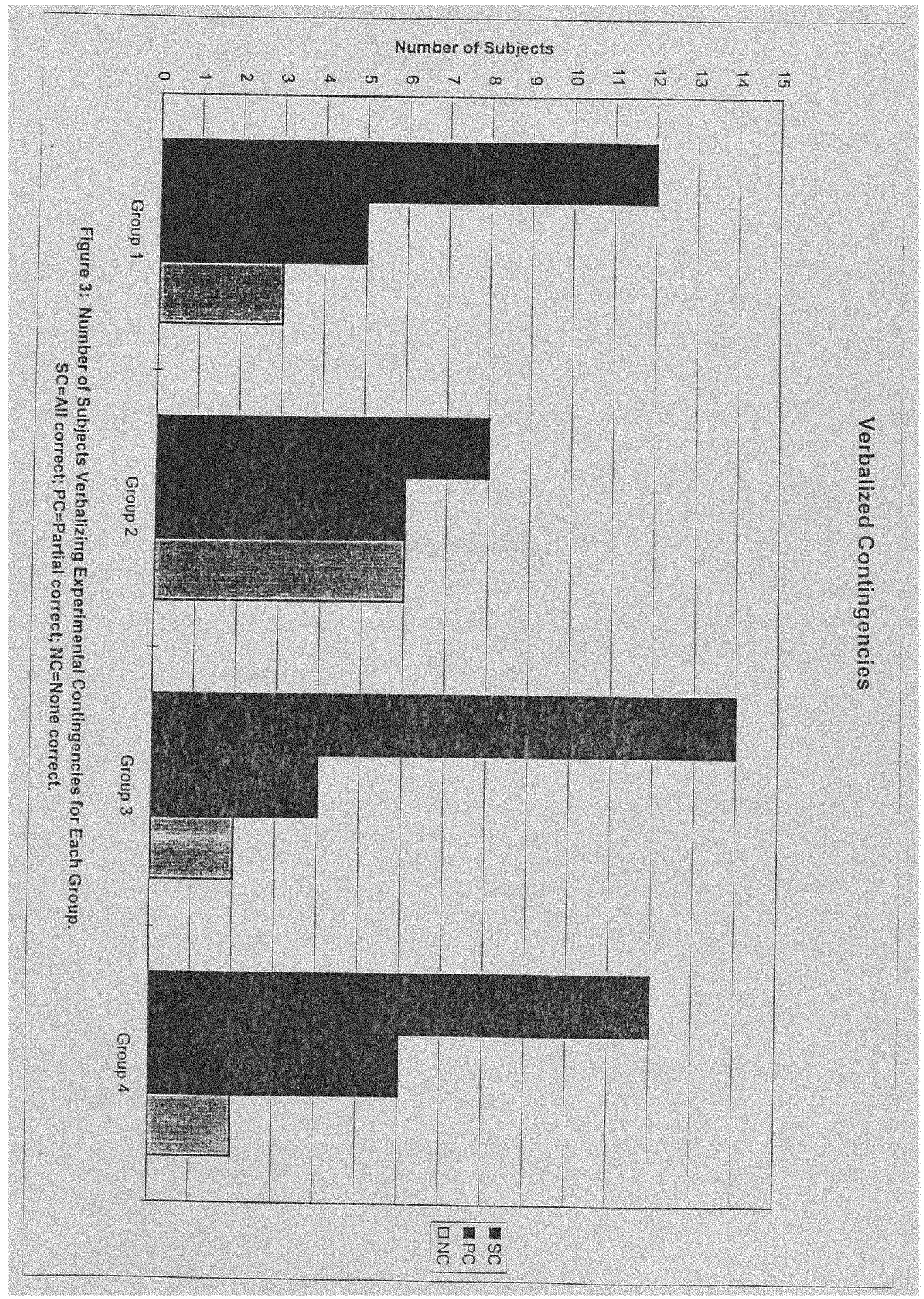


Appendix C 


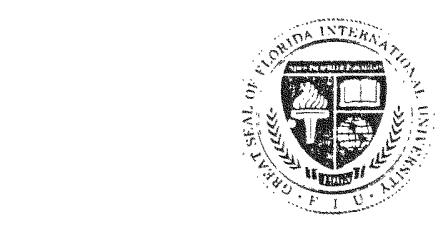

\title{
Florida International University
}

\author{
Explanation \\ The Effects of Verbal Behavior on Differential Responding in a \\ Matching-to-Sample Task.
}

Noel Crooks, 348-2880; Dr. Jacob Gewirtz, 348-3375; Dr. Martha Pelaez, 348-2090;

Dr. Michael Markham, 348-1230.

As the title suggests, this experiment will look at the influence of verbal feedback on a series of tasks. One area of controversy in the study of rule-following behaviors centers around the role of verbal behavior in acquiring a rule. Therefore, two main questions will be addressed in this study.

First, to what extent does experimenter feedback affects the subject's performance on a matching task. Second, to what extent would such an interaction affect the generalization of a specific response to similar contexts.

You will be required to match a series of items by touching a computer screen. These responses based on the cues given by the experimenter will be scored.

We thank you for your help in this study. If you are interested in learning more about rule-following, verbal behavior in adults and direct contingencies, you are welcome to talk with us at the Behavior Analysis laboratory or read the following articles listed below. These concepts are generally studied by experimental behavior analysts and may be covered in courses EAB 3002 . We will be analyzing the data during the spring. If you would like to know more about the results of the study, you can contact us at the lab in the fall semester.

\section{References}

Cerutti, D.T. (1989). Discrimination theory of rule-governed behavior. Journal of the Experimental Analysis of Behavior. Vol. 51, No. 2, 259-276.

Lowe, C.F., Beasty, A. \& Bentall R.P. (1983). The role of verbal behavior in human learning: Infant performance on fixed-interval schedules. Journal of the Experimental Analysis of Behavior. Vol. 39. No. 1, 157-164. 


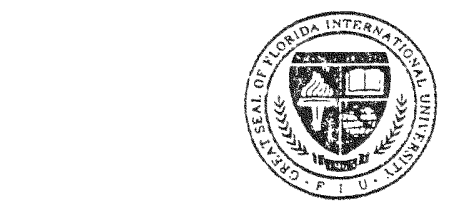

\section{Florida International University}

Informed Consent.

The Effects of Verbal Behavior on Differential Responding in a Matching-to-Sample Task.

I freely and voluntarily consent to be a participant in the research project entitled The Effects of Verbal Behavior on Differential Responding in a Matching-to-Sample Task to be conducted at Florida International University during the summer semester of 1996 with Noel Crooks as principal investigator. I have been told that the experiment will last no longer than 90 minutes during my visit.

I understand that the purpose of this research is to investigate the influences of environmental cues on conditional responding. I understand that there are no known risk involved in my participation in this experiment. I have been told that my performance will be kept strictly confidential. Data will be identified only by a code number and my individual performance will not be revealed by to anyone without my expressed permission. I will be one of 80 undergraduates tested.

I understand that I may withdraw my consent and discontinue participation in this research project at any time with no negative consequences. I understand that the experiment involves only one visit to the laboratory. I have been given the right to ask questions concerning the procedure and such questions have been answered to my satisfaction.

I understand that if I desire further information about this research I should contact Noel Crooks at 348-2880, Dr. J. Gewirtz at 348-3375, or Dr. M. Pelaez at 348-2090. I have been offered a copy of this informed consent form.

I have read and I understand the above.

Participant's signature

Date

I have explained and defined in detail the research procedure in which the participant bas agreed to participate, and have offered him/her a copy of this informed consent form.

Principal investigator's signature

Date

Department of Psychology - College of Arts \& Sciences

University Park, Miami, Florida 33199

(305) 348-2880 - TDD. via FRS 1-800-955-8771 - FAX (305) 348-3879

Equal OpportuntryfEqual Access Employer and Instrution 
INSTRUCTIONS

1. PLEASE SELECT ONE OF THE TWO STIMULI AT THE BOTTOM OF THE SCREEN BY PRESSING KEY 1 OR KEY 2.

2. THE LIGHTS, COLORS AND MUSIC CREATED BY THE COMPUTER INDICATES A CORRECT SELECTION.

3. TRY TO FIGURE OUT THE RESPONSE RESPONSIBLE FOR THIS CORRECT SELECTION, THAT IS, WHAT CAUSES THE LIGHTS, COLORS AND MUSIC TO APPEAR.

4. IN PHASES WHERE A TONE IS HEARD BEFORE THE ITEMS ARE PRESENTED, TRY TO FIGURE OUT THE ROLE OF THIS TONE, THAT IS, WHAT IS THE CORRECT SELECTION WHEN THIS TONE IS PRESENTED?

5. A BLANK SCREEN INDICATES THE END OF EACH PHASE OF THE EXPERIMENT. (FOUR PHASES WILL BE PRESENTED). 
WHAT WERE THE CORRECT RESPONSES IN THIS EXPERIMENT?

WAS THERE A GENERAL RULE WHICH YOU FOLLOWED?

IF SO, WHAT WAS THIS RULE? 